\title{
SOBRE UNA PARTICULAR ICONOGRAFÍA DEL TRIUNFO DE BACO EN DOS MOSAICOS ROMANOS DE LA BETICA
}

\author{
Guadalupe LÓPEZ MONTEAGUDO
}

CSIC

\section{Resumen}

La perspectiva frontal y la presencia de centauros, sustituyendo o guiando a los felinos que tiran directamente del carro del dios en la iconografía canónica del Triunfo dionisiaco, son variantes iconográficas que se documentan en dos mosaicos hispano-romanos. El análisis de los paralelos con otras representaciones musivas, pone de manifiesto la contaminación del Triunfo de Dionisos con el Triunfo de Neptuno y su posible relación con ideas de prosperidad e inmortalidad.

\section{Summary}

Among the scenes of Dionysus riding in triumph in his leopard-drawn chariot, two iconographic variations are offered on two roman-spanish mosaic pavements from the Betica: the frontal scheme and the chariot drawn by centaurs. The analysis of the cióse parallels shows the contamination between the dionysiac Triumph and the Triumph of Neptune and the connection with the ideas of good fortune and immortality.

Entre el numeroso grupo de representaciones del Triunfo báquico que ha dado la musivaria hispano-romana, cuyo número se eleva por el momento a dieciséis ejemplares, destacan dos pavimentos procedentes de la Bélica, Ecija (Sevilla) y Alcolea (Córdoba), cuya rara tipología los aparta del resto de los mosaicos hispanos con el mismo tema ${ }^{1}$. La sustitución de los animales que tiran del carro del dios por centau-

\footnotetext{
${ }^{1}$ A los ejemplares ya conocidos de Alcolea (Córdoba), Baños de Valdearados (Burgos), Cabra (Córdoba), Caesaraugusta (Zaragoza), Ecija (Sevilla), Itálica (Sevilla), Liédena (Navarra). Tarraco (Tarragona), Tiermes (Soria) y Torre de Palma (Portugal), han venido a sumarse en los últimos años los nuevos Triunfos de Ándelos (Navarra), Ecija (Sevilla) dos ejemplares, Fuente Álamo (Córdoba), Olivar del Centeno (Cáceres) y Torre Albarragena (Cáceres), cf. SAN NICOLÁS PEDRAZ, 1994, 1289-1304.
} 
ros no es desconocida en la musivaria romana, ni tampoco en otros soportes, siendo realmente frecuente en los sarcófagos de los siglos II y III, donde la presencia de los centauros tiene una clara connotación funeraria (TURCAN, 1966, 504-509). Sin embargo, su excepcionalidad dentro del conjunto musivario hispano y la perspectiva utilizada en ambos "triunfos" hace que estos dos ejemplares, que se fechan en la segunda mitad del siglo II, se aparten del resto de sus vecinos geográficos y se hallen más conectados con otros de fuera de la Península Ibérica y, por consiguiente, muestren al igual que sus paralelos la misma contaminación con el Triunfo de Neptuno, como tendremos ocasión de ver a lo largo de estas páginas.

El mosaico del Triunfo báquico (Lám. 1), procedente de la Colonia Augusta Firma Astigi, eleva a tres el número de los pavimentos astigitanos decorados con esta temática (FERNANDEZ GÓMEZ, 1997, 75-97, láms. I-IV; ID., 1998, 34-38)². Se trata de un espléndido mosaico polícromo, con predominio de las teselas azules y verdes, del que desgraciadamente solo se conoce la mitad del mismo, 7,80 x 4,20 m., con unas medidas originales de alrededor de 15 x $8 \mathrm{~m}$. y una composición a base de círculos y octógonos cóncavos en torno a un gran medallón central, realizados todos en sogueado de dos cabos, similar a la que presenta el mosaico jiennense de los pájaros de Beas de Segura, que se fecha en el siglo IV (BLAZQUEZ ET ALII, 1986, 227-232, figs. 1-2), pudiéndose enmarcar en el "Kreissystem III" de Salies, cuyos ejemplos más tempranos en policromía, de Italia, Galia y Grecia, pertenecen a la época de los Antoninos, documentándose en Siria en ejemplares ya tardíos (SALIES, 1974, 15, 57-64, 164-165, Bild 4, 57)\

A juzgar por lo conservado, que es casi toda la mitad inferior del pavimento, se puede reconstruir en su totalidad la superficie musiva del Triunfo báquico de Ecija,

\footnotetext{
${ }^{2}$ De antiguo se conocía el mosaico del Triunfo báquico, que se conserva en el Museo Arqueológico de Sevilla \{CMREIV, 1982, 13-19, láms. 1-2, 38-39). En 1984 se descubrió otro Triunfo báquico, muy destrozado-que fué dado a conocer por I. Rodríguez Temiño y E. Núñez en el Anuario Arqueológico de Andalucía, 1985 (1987), 321-325, y presentado por el equipo que realiza el Corpus de Mosaicos Romanos de España al VI CIMA (Túnez 1996), cf. LÓPEZ MONTEAGUDO ET ALII, 1996, en prensa; LÓPEZ MONTEAGUDO, 1997, en prensa, con todo el estudio iconográfico y de los paralelos. Agradezco a D. Fernando Fernández, Director del Museo de Sevilla, el haberme permitido consultar el texto y las ilustraciones de su artículo publicado en la Revista de Arqueología (1998), cuando aún estaba en prensa.

El pavimento fué descubierto en 1977 al realizarse unas obras de cimentación en la casa núm. 1 de la plaza de Santiago, donde se procedió a una excavación de urgencia dirigida por el Director del Museo Arqueológico de Sevilla, D. Fernando Fernández, que fué imposible continuar en la casa contigua bajo la cual se extendía también el pavimento. La parte salvada se encuentra actualmente, a la espera de ser restaurada y expuesta, en el Museo Histórico Municipal de Ecija. Agradezco a D. Fernando Luna todas las gestiones realizadas para facilitarme las fotografías del mosaico en el momento de su descubrimiento, ya que en la actualidad no es posible contemplarlo directamente.
} 
presidida por un gran círculo central, de casi $2 \mathrm{~m}$. de diámetro, en torno al cual se disponen ocho círculos de menor tamaño, de $0,66 \mathrm{~m}$. de diámetro, cuatro por encima de aquel y cuatro por debajo, doce semicírculos en la unión del tapiz con la orla de enmarque y veinte espacios octogonales y hexagonales de lados curvos, decorados en su mayoría con figuras del thiasos dionisiaco. En los dos círculos de la parte inferior del pavimento se han representado las cabezas de Sileno, con pámpanos en la cabeza, y Pan, con los típicos cuernecillos, delante de sendos tympanoi. Los dos hexágonos, situados en la unión con la orla de enmarque, van decorados con una bacante recostada de espaldas junto a un gran kylix, sosteniendo el tirso y una pequeña crátera, y un sátiro que corre hacia ella, con la nebris flotando sobre la espalda y vertiendo en un vaso el gran kantharos, que lleva en la mano derecha. En los tres semicírculos laterales se han figurado tres animales báquicos, gacela, león y pantera, todos en movimiento hacia la derecha. Los bustos de las Estaciones, quedan solo las personificaciones del Verano y del Otoño con sus atributos característicos, ocupan los dos círculos situados debajo del medallón central, por lo que hay que suponer que la Primavera y el Invierno decoraban otros dos círculos situados simétricamente en la zona superior. La personificación del Verano lleva manto de color azul cubriendo el hombro izquierdo, la hoz sobre el derecho y corona de espigas adornando la cabeza. El busto del Otoño, cubierto con túnica de mangas y escote redondeado, corresponde a un hombre de edad madura, con barba y dos racimos de uvas a ambos lados de la cabeza. Los espacios octogonales están decorados con escenas mitológicas: Leda en pie y de espaldas, con manto que le cubre las piernas y deja al descubierto el resto del cuerpo, en el momento de ser poseída por el cisne, como en lucernas de los siglos III (DENEAUVE, 1969, 166, lám. 68), o en esculturas y relieves de los siglos I-III \{LIMC VI, "Leda", núms. 79-101), iconografía que no se documenta en la musivaria romana y que solo puede ponerse en relación con la escena del mosaico chipriota de Palaepaphos (Kouklia), fechado a fines del siglo II o a comienzos del III, que representa el momento inmediatamente anterior al de Ecija (MICHAELIDES, 1987, núm. 20, lám. IX); el dióscuro Cástor de pie delante del caballo, en una postura similar a la de los Dióscuros del mosaico del Triunfo de Dionisos de la Casa de Dionisos en Nea Paphos (DASZEWSKI, MICHAELIDES, 1989, 27, figs. 13-14), de la Amazona de la Casa de Orfeo, en este mismo lugar (NICOLAOU, 1984, 222-225, fig. 7), fechados ambos entre 250 y 300, o de varios personajes representados en el pavimento de la Casa de los Caballos de Cartago, ca. 300-320 (SALOMONSON, 1965, láms. XLIXLIII, LI y LIX); y Orfeo en pie entre dos árboles, tocando la lira y acompañado por una figura femenina, que aparece sentada de espaldas sobre una roca al fondo, tal vez identificable con Eurídice. La iconografía de Orfeo en pie, típica de las representaciones del rey músico en los infiernos en la cerámica apulia del siglo IV a.C. (LIMC VII, «Orpheus», núms. 72-84), es muy rara en la musivaria romana y, sin embargo, 
en el mosaico de Ecija la presencia al fondo de Eurídice avala la identificación de este momento del mito. En uno de los espacios hexagonales, que rodean el círculo central, se ha figurado a Narciso sentado en una roca entre dos árboles, con manto que le cubre la pierna derecha, contemplando su imagen en el agua de la fuente, iconografía muy frecuente en la pintura pompeyana (LIMC VI, "Narkissos", núms. 1-7, 27-32, 45-50) y también en la musivaria romana, documentándose en tres pavimentos de Antioquía, fechados de comienzos del siglo II a fines del III (LEVI, 1947, láms. Xb, XXIIIc y XLVa), en el emblema de un mosaico hallado recientemente en la antigua ciudad búlgara de Philippopolis, que se fecha en la primera mitad del siglo III (KESSIAKOVA, 1994, 166-170, lám. LXXXVII,1), en uno de los espacios hexagonales del pavimento procedente del caldarium de las Grandes Termas de Thina, de fines del siglo III (MASSIGLI, 1912, núm. 9, lám. VI,2), y en un mosaico de la Casa de Dionisos en Nea Paphos, datado en 250-300 (ELIADES, 1986, 17-18). En el otro hexágono conservado puede verse una escena marina fragmentaria, de la que solo se aprecia la cola de un animal marino cabalgado por un amorcillo desnudo, con paralelos en un mosaico de Timgad de la segunda mitad del siglo III (GERMAIN, 1969, 109-110, núm. 161, lám. LII) y sobre todo en relieves, pinturas y camafeos (LIMC III, "Eros/ Amor, Cupido", núms. 396-397, 410-418).

La escena figurada en el círculo central (Lám. 2), de la que solo queda desgraciadamente la mitad inferior, muestra a Dionisos de frente sobre un carro tirado por dos parejas formadas por un centauro y una centauresa con subjugium, que galopan vistos en perspectiva frontal y en posición rampante, como si se vieran desde abajo, lo que produce una mayor sensación de movimiento. En el grupo de la izquierda el centauro, situado al extremo y casi perdido de cintura para arriba, lleva un tympanon, como en el mosaico de Alcolea (vid. infra), mientras que la centauresa, con manto de color azul sobre la espalda y cinta transversal entre los senos, vierte desde lo alto con la mano izquierda el rython en la pátera que sostiene en la mano derecha, posición idéntica a la que presenta uno de los centauros del panel rectangular de El Djem (vid. infra). La presencia de estos atributos emparenta al grupo de Ecija con el triunfo dionisiaco de Tenuta de Fiorano aunque en este último los centauros, al igual que en El Djem, estén representados de perfil (vid infra). En el grupo de la derecha la centauresa, que en este caso ocupa el extremo y va vestida como la anterior, levanta los brazos tocando los crótalos (?), mientras que el centauro, de edad madura, crines de color marrón y barba, levanta el brazo derecho sobre su cabeza, portando la lira como en los mosaicos de Alcolea, El Djem, Nea Paphos y Sheik Zouéde, todos pertenecientes al grupo de "Triunfos báquicos" vistos de perfil (vid. infra). Entre ambas parejas se puede ver el tiro, la statera y la caja recta del carro con ruedas de ocho radios, dentro de la que se halla la figura estante del dios. Va vestido con túnica 
blanca ceñida a la cintura y manto de color azul, que debía flotar alrededor de la cabeza, cuyos extremos ondean a ambos lados de la cintura, como en los Triunfos báquicos de Alcolea, Tenuta de Fiorano y Acholla (vid. infra). Tipológicamente, este mosaico forma parte del grupo de "Triunfos báquicos" vistos en perspectiva frontal y con el carro tirado por centauros. Sin embargo, el paralelo más próximo, tanto para la figura del dios con la ropa ondeante y ceñida a la cintura, como para la postura rampante de los centauros, se encuentra en el mosaico del Triunfo de Baco de Acholla, de comienzos del siglo II, aunque aquí el grupo esté representado de tres cuartos \{vid. infra). Las características estilísticas y técnicas del pavimento astigitano, como es la utilización de los escorzos, las perspectivas, los juegos de sombras y el pequeño tamaño de las teselas, $c a$. un centenar por dm2, llevan a F. Fernández a datarlo en la segunda mitad del siglo II, época de los Antoninos o de los Severos, en la que aún están vigentes en la musivaria los conceptos artísticos de raíz pictórica.

Lo más interesante del mosaico de Ecija es la posición frontal del carro de Dionisos, iconografía desconocida, hasta el momento, en la musivaria hispana y muy rara en los triunfos dionisiacos, ya que solo se documenta en los mosaicos griegos de Corinto y Dión, así como en el tunecino de El Djem, cuyos carros van tirados igualmente por centauros, y por felinos en un panel de Antioquía. En otros soportes el mismo esquema compositivo frontal, con los centauros tirando directamente del carro de Dionisos, aparece en un camafeo del Museo del Louvre, de época de Augusto (Lám. 3), aquí con dos pares de centauros y centauresas simétricamente divergentes hacia los lados (LIMC III, "Dionysos/Bacchus", núm. 216), como en el mosaico de Ecija, y en una tela copta del Victoria and Albert Museum (Lám. 4), solo con dos centauros divergentes vistos de perfil, que vuelven la cabeza hacia el centro, uno tocando el doble aulós y el otro portando el lyknon (LIMC III, "Dionysos in per. or.", núm. 135), como en el mosaico del Triunfo báquico de Acholla (vid. infra).

El pavimento que decora la sala norte de la Casa de los Mosaicos en Corinto, fechado entre finales del siglo II y comienzos del III, ofrece una representación del Triunfo de Dionisos muy próxima al mosaico astigitano (Lám. 5). El dios, acompañado de Sileno, aparece en posición frontal sobre un carro tirado por dos panteras marinas guiadas por sendos centauros también marinos, figurados de tres cuartos y avanzando en dirección opuesta hacia los extremos, de forma que dejan ver el frente y los laterales rectos de la caja del carro, adornada con una moldura. Asimismo, se ha figurado el timón vertical, rematado en pomo, y la statera cuyos extremos se apoyan sobre el lomo de los felinos. El dios sostiene un rython, como en otro triunfo báquico descubierto en Ecija (LÓPEZ MONTEAGUDO, 1997, en prensa), mientras que los centauros, uno de edad madura y barbado, y el otro representado como un joven imberbe, portan sendos kantharoi (WEINBERG, 1960, 113-122, lám. 57,1). Lo más 
sorprendente de este mosaico es la naturaleza marina de los felinos y de los centauros, que evidencia la contaminación con los triunfos de Neptuno, acrecentada por la presencia de las grandes ánforas portadas por los centauros, como en una pintura pompeyana con representación del Triunfo de Neptuno y Anfitrite, donde el recipiente es llevado por un tritón (vid. infra).

Prácticamente igual, hasta en los más mínimos detalles, es el Triunfo de Dionisos que decora el panel central de un gran mosaico hallado en las excavaciones llevadas a cabo, en la última década, en la villa de Dionisos de Dión (Lám. 6), con una cronología también en torno al año 200, con la única diferencia de que en este último se ha conservado la cabeza del dios, que en Corinto casi ha desaparecido, y que las figuras de Dionisos y de los centauros son más proporcionadas que en Corinto, donde los centauros, vistos en primer plano, ofrecen un aspecto más voluminoso que el dios (BCH, 112,2, 1988, 747, fig. 69; PANDERMALIS, 1997, 51-60).

El mosaico núm. 3 procedente del oecus de la Casa de Tertulia en El Djem, que se data $c a$. 200-220, tiene un gran interés iconográfico ya que, a pesar de su mal estado, se han conservado dos escenas de Triunfo báquico en el que intervienen centauros. Interesa el Triunfo representado en el círculo central (Lám. 7), del que falta la mitad inferior, por constituir un paralelo para el mosaico de Ecija, aunque la perspectiva no es enteramente frontal, sino que tanto el carro como los personajes que intervienen en la escena aparecen ligeramente virados hacia la derecha. Sin embargo, la imagen conserva algunos de los convencionalismos utilizados en las representaciones frontales, como son los animales de los que tiran dos centauros lampadóforos, que divergen hacia los lados para dejar ver la parte delantera de la caja de líneas rectas. Dionisos aparece majestuosamente de pie sobre el carro, vestido con túnica larga y llevando el tirso en la mano derecha; le acompaña una nike, que pone la corona sobre la cabeza del dios, y un personaje masculino barbado, que tal vez pueda identificarse con Sileno, aunque Foucher le encuentra cierta semejanza con Septimio Severo y piensa que incluso podría tratarse del propietario de la casa (FOUCHER, 1961, 48-52, lám. XXI b).

En el panel procedente de la Casa del Triunfo de Dionisos, en Antioquía, del que solo se conserva la mitad izquierda, se ha representado el triunfo del dios en el centro de la composición, acompañado de su cortejo (Lám. 8). Dionisos aparece solo, de pie en el carro tirado por una pareja de tigres, en perspectiva frontal. Va vestido con túnica larga, lleva el tirso en la mano derecha y adorna su cabeza con corona de hojas y flores. La correcta posición de los animales, estáticos frente al espectador, permite ver a los lados las dos ruedas del carro y, entre ellos, la caja curva del mismo. Como dice Levi, la perspectiva frontal de este grupo proporciona al conjunto, a pesar de su inmovilidad, un fuerte carácter de composición centralizada, en la que el movimiento parte del centro y se va incrementando gradualmente hacia los lados. A la derecha del dios se ha represen- 
tado a Ariadna, estante, con el brazo extendido hacia la derecha sosteniendo un cetro, junto a la cista de los misterios, seguida de un sátiro o una ménade con antorcha en la mano derecha y el tympanon en la izquierda, Pan sosteniendo con ambas manos un gran kantharos, y una ménade en frenética danza con una crátera sobre su hombro. Se fecha al final de los Antoninos (LEVI, 1947, 93-99, lám. XVI c).

Ya Dunbabin, en su estudio acerca de los Triunfos báquicos representados en los mosaicos del Norte de África, apuntaba que el esquema frontal es el que mejor se adapta para decorar un espacio circular (DUNBABIN, 1971, 57), como ocurre en un plafón de estuco policromado, procedente de un hipogeo de Sousse (Lám. 9), que muestra a Dionisos de pie sobre el carro de caja curva, conducido por un par de panteras (FOUCHER, 1953, 88, pl. la), o en textiles coptos en los que los triunfos báquicos, caracterizados por la centralidad, la frontalidad y la simetría típicas del arte orientalizante, decoran el círculo inscrito en el cuadrado que forma la tela, aunque este esquema frontal no es excluyente ya que también se dan las posiciones de tres cuartos (LENZEN, 1960, 14-17, pl. 1, 2 y 5b; LIMCIII, "Dionysos in per. or.", núms. 133-137). El mismo condicionamiento impuesto por la forma circular del espacio tiene lugar en los mosaicos de Ecija y El Djem, no así en los de Corinto, Dión y Antioquía, donde la escena se desarrolla en un gran espacio rectangular, como acabamos de ver. Al parecer, el prototipo para el esquema frontal de los triunfos báquicos remonta al arte griego arcaico, en el que frecuentemente se representa el carro tirado por dos pares de caballos en la cerámica de figuras negras (LIMC III "Dionysos", núms. 765-766). Según Dunbabin, la posición frontal en los mosaicos de Triunfo báquico resultaría ser una variante de las representaciones de los sarcófagos, en la que el artista, preservando los motivos principales básicos, adapta los movimientos originales a derecha e izquierda de los paneles rectangulares de los sarcófagos al espacio circular del centro del pavimento (DUNBABIN, 1971, 64-65).

Al contrario de lo que ocurre en los Triunfos dionisiacos, la posición frontal es bastante frecuente en los Triunfos de Neptuno (NEIRA JIMÉNEZ, 1996, 555-576, láms. I, II, V, VI), representados en los mosaicos tunecinos de Acholla y La Chebba, en el itálico de Fano y, ya en el Oriente, en los de Seleukia del Eufrates y Misis Mopsuhestia, utilizándose la misma perspectiva frontal en los Triunfos de Neptuno y Anfitrite de Utica (CMT 1,2, núm. 205, fig. 2, láms. XXXIII-XXXVI) y Constantina (BARATTE, 1973, 313-334). Un caso interesante lo constituye el mosaico procedente de las termas de Kronion en Olimpia, en el que se ha figurado un tritón barbado, en posición igualmente frontal, con tridente a la manera de Neptuno, guiando por las bridas a dos parejas de hipocampos que galopan en el mar en dirección divergente, atestiguando la contaminación con el conocido tipo de thiasos marino (KANKELEIT, 1994, 135-138, fig. 1). 
En el mosaico tunecino de la Casa del Triunfo de Neptuno en Acholla (Lám. 10), que se data $c a$. 170-180 y se conserva en la sala de recepción del cementerio americano de Cartago, aparece Neptuno en pie sobre un carro visto de frente y tirado por dos hipocampos, figurados de tres cuartos, cuya posición avanzando hacia los extremos deja bien visible la caja del carro, adornada con molduras y una placa (GOZLAN, 1992, núm. 53, láms. L-LI y LXXV). Esta es de forma cuadrada, como en los mosaicos de Ecija y el Djem y, en clara analogía con los triunfos dionisiacos de Corinto y de Dión, se ha representado sobre el eje del carro el timón vertical, rematado por un pomo, la statera apoyada por sus extremos sobre el lomo de los caballos marinos, y el subjugium que desde la parte trasera llega hasta el pecho de los animales, a modo de collar. Sin embargo y a diferencia del pavimento astigitano y de los Triunfos marinos vistos en perspectiva frontal, en Acholla solamente se han figurado dos hipocampos tirando del carro del dios, aproximándose de esta forma a las representaciones canónicas de los Triunfos dionisiacos, con los que también tiene en común la forma cuadrada de la caja del carro (NEIRA JIMÉNEZ, 1996, 555-576).

En el mosaico tunecino de La Chebba (Lám. 11), fechado a mediados del siglo II y por consiguiente el ejemplo más antiguo de Triunfo de Neptuno en posición frontal, el dios aparece majestuosamente de pie sobre un carro de caja curva, con nimbo alrededor de la cabeza y el tridente en la mano izquierda. El carro, abierto por detrás como indican los laterales en disminución y en el que se aprecia el timón y la statera, va tirado por cuatro briosos corceles marinos con subjugium, guiados por un centauro y una centauresa, de naturaleza también marina, que sostienen el tirso y el pedum respectivamente ( $I \quad n \quad v$.Mos.Af. II, 86). La introducción de estas figuras en el Triunfo de Neptuno emparentan la escena tunecina a los Triunfos dionisiacos de Corinto y Dión y, en consecuencia, al pavimento de Ecija, poniendo de manifiesto una vez más la contaminación entre ambos tipos de representaciones.

El medallón circular del mosaico bícromo de Fanum Fortunae (Fano) y el pavimento fragmentario de Seleukia del Eufrates, de comienzos y mediados del siglo III respectivamente, pueden parangonarse hasta cierto punto con el de la Chebba en la posición majestuosa del dios y en los cuatro briosos hipocampos, que tiran del carro hacia los extremos, aunque en ellos falten los tritones. En el mosaico de Fano (Lám. 12) el dios aparece de pie sobre el carro, en una posición un tanto violenta, sosteniendo el tridente hacia abajo en la mano derecha y el manto en la izquierda. El carro, de caja curva con laterales en disminución y abierto por detrás, como el de La Chebba, va tirado por cuatro hipocampos bridados que impiden la vista del timón y de la statera y que, sin embargo, dejan ver las dos ruedas de ocho radios en una perspectiva totalmente irreal (BATTISTELLI, DELI, 1983, 106-107, fig. 105). En el mosaico de Seleukia (Lám. 13) los hipocampos, que tiran del carro hacia los extremos, permi- 
ten ver la caja curva del carro con el timón y la statera sobre los lomos de los dos hipocampos centrales, como en el ejemplar norteafricano de La Chebba, aunque aquí falten los centauros (PARLASCA, 1983, 227-234, Figs. 5-7).

Del pavimento de Misis Mopsuhestia (Lám. 14), fechado a mediados del siglo III, solamente se ha conservado parte de la figura del dios Neptuno que, sosteniendo el tridente en el brazo derecho levantado, aparece de pie sobre el carro de caja curva en la que se aprecia con toda claridad el timón. La particularidad más sobresaliente de esta representación es que el carro va tirado directamente por dos tritones de una sola cola pisciforme, portando sus atributos característicos, que, a la manera de los animales, llevan los arreos cruzados sobre el torso y los extremos de la statera sobre sus hombros (BUDDE, 1969,1, 94; 1972, II, láms. 29-30), aproximándose de esta forma al mosaico pompeyano del Triunfo de Neptuno y Anfitrite de la Casa del Granduca di Toscana, en el que también el carro va tirado directamente por dos tritones, aunque en perspectiva de perfil (vid. infra). El pavimento de Misis Mopsuhestia, constituye, por consiguiente, el único ejemplo de Triunfo de Neptuno, visto en perspectiva frontal, en el que los tritones no guían a los animales que tiran del carro, sino que son ellos mismos los que asumen este papel, como ocurre con los centauros del Triunfo de Ecija, siendo ambas representaciones un buen ejemplo de la contaminación entre los triunfos báquicos y los marinos ${ }^{4}$.

La otra particularidad del mosaico astigitano, además de la perspectiva frontal, es la presencia de centauros llevando el carro de Dionisos, como en los citados Triunfos báquicos de Corinto, Dión y El Djem, aunque en estas escenas los centauros no sustituyen a los animales que tiran del carro de Baco, sino que aparecen guiándolos, de forma similar a la de los centauros marinos representados en el mosaico del triunfo de Neptuno de La Chebba. La sustitución de los felinos, que tiran directamente del carro del dios siguiendo la iconografía canónica de los Triunfos dionisiacos, por dos centauros tiene lugar en las representaciones vistas de perfil o de tres cuartos, particularidad iconográfica bastante usual en gemas (Lám. 15), objetos de plata, monedas (Lám. 16) o sigillata (LIMC VIII, "Kentauroi et Kentaurides", núms. 471-474, 479, 484 y 488), y sobre todo en los sarcófagos (Lám. 17) de los siglos II y III (MATZ, 1968, II, 286-301; 1969, III, 388-400; 1975, IV, 452-466), o en las mesas-sigma (Lám. 18) de la tarda antigüedad (PARRISH, 1995, 326, fig. 14), donde la superficie alargada se presta más a esta iconografía que a la perspectiva frontal. En la musivaria romana la posición de perfil o de tres cuartos es más frecuente que el esquema fron-

${ }^{4}$ El mismo tipo iconográfico se encuentra en un camafeo del Kunsthistorischesmuseum de Viena, datado a finales del reinado de Augusto, en el que que cuatro tritones tiran directamente del carro triunfal de Augusto (LIMC VIII, "Tritones", núm. 62). 
tal, aunque mucho menos usual que la convencional del carro de Baco tirado por felinos, y sin embargo tampoco es desconocida en la musivaria hispana, ya que se la encuentra en otro mosaico procedente igualmente de la Bética.

El mosaico del thiasos báquico de Alcolea (Lám. 19), que se fecha entre 160-170, forma un cuadrado de $2,60 \mathrm{~m}$. de lado con una composición radial de ocho rectángulos, que parten de un octógono central y determinan otros tantos espacios triangulares, acabados en los ángulos en círculos y en medios círculos en el centro de los lados \{CMRE III, 1981, núm. 21, láms. 25-30, 85-88) ${ }^{5}$, pudiéndose considerar una variante del "Oktogonsystem VI, Zentralkomposition" (SALIES, 1974, 12-14, 56-57, Bild 3,43). Esta composición se repite exactamente igual en otros dos pavimentos cordobeses de finales del siglo II, procedentes del solar de la antigua Colonia Patricia, el llamado de las Estaciones (LÓPEZ MONTEAGUDO, 1991, 365-372, láms. I-II) y el mosaico de Baco (CMRE III, 1981, núm. 12, láms. 13-16). El mismo esquema se documenta, sin los círculos de los ángulos y los medios círculos situados en el centro de los lados, en el mosaico del Nacimiento de Venus de Cártama (CMRE III, 1981, núm. 61, lám. 70) y en el de la Medusa de Mérida (CMRE I, 1978, núm. 57, lám. 88 B), que se datan ya a fines del siglo II o a comienzos del siguiente, lo que hace pensar en la existencia de un taller que trabajaba en la Bética, cuyo radio de acción se extendía a zonas próximas.

La originalidad de la composición cordobesa radica en la disposición de las figuras, de forma que el carro del dios, tirado por centauros, ocupa el octógono central, mientras que los ocho rectángulos radiales van decorados con las figuras del thiasos, alternando los sátiros y las ménades; los bustos de los vientos ocupan los círculos de los ángulos y el resto de los compartimentos lleva una decoración vegetal formada por hojas trífidas en los semicírculos, hederae y hojas de vid en los triángulos curvilíneos. El Triunfo de Baco (Lám. 20), que preside la composición, se ha representado en perspectiva de tres cuartos, excepto en la figura del dios que, en pie y coronado de pámpanos, aparece visto de perfil guiando su carro con la mano derecha y sosteniendo el tirso en la izquierda. Dionisos viste túnica de manga larga, ceñida a la cintura, y manto flotando por detrás de la espalda y de la cabeza, como en los pavimentos de Ecija (vid. supra), Tenuta de Fiorano y Acholla (vid. infra), reflejando el movimiento de la veloz carrera de los centauros que tiran directamente del carro. La posición estante de Dionisos solo dentro del carro, habitual en los mosaicos norteafricanos (DUNBABIN, 1971, 52-65; FOUCHER,

\footnotetext{
${ }^{5}$ El mosaico, que actualmente se conserva en el Museo de Córdoba, fué descubierto en 1959 formando parte del programa iconográfico de la villa romana de Alcolea, situada en la orilla derecha del Guadalquivir, a unos $11 \mathrm{Km}$. en dirección NE. de Córdoba. La villa, que ya se conocía desde 1957, estaba pavimentada con otros mosaicos figurados de gran interés, como son los de la Loba y los gemelos y Teseo y el Minotauro (GARCÍA Y BELLIDO, 1965, 7-19; CMRE1E, 1981, núms. 23 y 24, fig. 14, láms. 32-35 y 89).
} 
1975, 55-61) y también en los de Ostia (BECATTI, 1961, 197, núm. 367, lám. LIII), Nea Paphos (DASZEWSKI, MICHAELIDES,1989, 24-27, fig. 12), Tréveris (PARLASCA, 1959,40-41, láms. 40-41) y Antioquía (vid. supra), sin embargo es poco frecuente en los ejemplares hispanos, donde únicamente se encuentra además de en Alcolea, en los pavimentos tardíos de Olivar del Centeno (Cáceres) y Tarragona (SAN NICOLÁS PEDRAZ, 1994, 1289-1304, lám. XII). Asimismo, la iconografía afeminada del dios, vestido con túnica de manga larga, que también aparece en estos últimos y en los triunfos hispanos de Caesaraugusta, Ecija, Cabra y Liédena (FERNANDEZ GALIANO, 1984, 97-120, figs. 1, 2,4,7 y 8), en los mosaicos de Antioquía (vid. supra) y Sheikh Zouéde (vid. infra), y que es usual en los pavimentos africanos, baste recordar los de Setif (DONDERER, 1988, 781-790, lám. la), varios de El Djem (vid. supra), Sousse, Cherchel, Saint Leu, Sabratha y Volúbilis (DUNBABIN, 1971, 53, n. 5), responde a la descripción de las fuentes antiguas (Paus. 5, 19,6; Athen. V 200; Nonnos, dion. XX 229-230) y perdura en el arte tardío de la parte oriental del imperio, de manera especial en los textiles (LENZEN, 1960, 2-4). El carro es de caja curva, adornada con una moldura, y cerrado por detrás; se aprecian con toda claridad las dos pequeñas ruedas de ocho radios y la statera que apoya en las espaldas de los centauros. Carros de caja curva y dos ruedas de seis u ocho radios se documentan en otros Triunfos báquicos hispanos, de los siglos III y IV, procedentes de Itálica (Sevilla), Fuente Álamo (Córdoba), Torre Albarragena (Cáceres) y Torre de Palma en Portugal (SAN NICOLÁS PEDRAZ, 1994, 1289-1304, láms. VII, IX y XI). Los centauros, ambos de sexo masculino, galopan briosamente hacia la derecha con la cabeza vuelta al espectador; van coronados de pámpanos y llevan pedum y dos de los atributos que ya aparecían en el mosaico de Ecija, un tympanon y una lira, esta última como en los mosaicos de Nea Paphos y Sheikh Zouéde (vid. infra), mientras que la presencia del tympanon le pone en relación con el mosaico bícromo de Tenuta de Fiorano (vid infra). En líneas generales el paralelo más próximo para el Triunfo de Alcolea, como ocurría en Ecija, lo constituye también el representado en el pavimento procedente de las Termas de Trajano en Acholla, con una cronología a comienzos del siglo II (vid. infra).

Ciñéndonos a las representaciones musivas de triunfos báquicos en los que, al igual que en Alcolea, los felinos han sido sustituidos por centauros, se comprueba que este tipo iconográfico no es privativo de una zona ni de una época determinada, sino que se documenta tanto en Oriente como en Occidente, con una amplia cronología. De perfil aparecen los centauros tirando del carro de Dionisos en el mosaico itálico de Tenuta de Fiorano y en los norteafricanos de Acholla y El Djem, y ya en el Oriente en los pavimentos de Nea Paphos, Gerasa, Sepphoris y Sheikh Zouéde.

En el mosaico en blanco y negro, probablemente del siglo II, hallado en una tumba descubierta en Tenuta de Fiorano (Lám. 21), cerca de la vía Appia, se ha represen- 
tado a Baco de pie en un carro esquemático, con rueda de ocho radios, tirado por dos centauros. El dios va desnudo, con manto sobre la espalda y adorna la cabeza con dos racimos de uvas a ambos lados, como en el pavimento de Sheikh Zouéde \{vid. infra) o en los mosaicos hispanos de Fuente Álamo y Baños de Valdearados (LÓPEZ MONTEAGUDO, 1998, en prensa). En la mano izquierda sostiene el tirso y con la derecha empuña las riendas. Los centauros, representados a galope, adornan su cabeza con pámpanos, llevan pedum en la mano derecha y en la izquierda uno el tympanon y el otro un rython que levanta volviéndose hacia el dios, aproximándose de esta forma al grupo de la izquierda del mosaico astigitano que lleva los mismos atributos \{vid. supra), aunque su posición de tres cuartos y el tympanon, que también se documenta en Alcolea, lo emparente más con este último (BLAKE, 1936,169, lám. 35,3).

El frigidarium de las Termas de Trajano en Acholla estaba pavimentado con un gran mosaico de forma rectangular, decorado con escenas de thiasos marino y dionisiaco y presidido por el Triunfo de Dionisos (Lám. 22), que se fecha ca. 115120 (PICARD, 1959, 78-95, láms. XI-XXI). Esta representación tiene el enorme interés de constituir el paralelo más próximo para los dos mosaicos hispanos, ya que se ha figurado al dios solo en el carro tirado por centauros en galope rampante, como si estuvieran vistos desde abajo, posición que recuerda muy de cerca a la representada en el mosaico astigitano, aunque en este último la perspectiva sea frontal. El carro, que es de caja curva decorada con moldura y relieves y ruedas de ocho radios, va tirado por un par de centauros figurados, como en Alcolea, de tres cuartos. Ambos llevan subjugium y portan el vano místico (lyknon), uno, y el otro un tirso y una antorcha. Dionisos aparece de pie sobre el carro, coronado de pámpanos, con tirso en la mano izquierda y crátera en la derecha. Lleva túnica que le cubre solo de la cintura hacia abajo y manto flotando alrededor de la cabeza, al igual que en Alcolea, cuyos extremos ondean, como en Ecija, a ambos lados de la cintura. La presencia de la crátera en la mano del dios, ilustración de la famosa pompé de Ptolomeo II Filadelfo, recogida en Atheneo (Deipn. V 200 ss.), donde se menciona uno de los triunfos en el que Dionisos ofrece una libación como símbolo de poder divino, se halla documentada entre otros en los triunfos hispanos de Ándelos (MEZQUIRIZ, 1987, 59-61), Ecija (LÓPEZ MONTEAGUDO, 1997, en prensa) e Itálica \{CMRE II, 1978, núm. 19, lám. 45), de los siglos II-III, y en los pavimentos ya tardíos de Torre de Palma (BLAZQUEZ, 1980, 125-131, fig. 2) y Baños de Valdearados \{CMRE XII, 1998, núm. 1, láms. 1-2 y 31). Fuera de Hispania, el mismo tipo iconográfico se atestigua en Ostia (BECATTI, 1961, 197, núm. 367, lám. Lili), Corinto \{vid. supra), Tréveris (PARLASCA, 1959,40-41, láms. 40-41), El Djem en el Museo del Bardo (FOUCHER, 1975, lám. XXI,2), Sepphoris (vid. infra) y Sheikh Zouéde \{vid. infra). Al contrario de lo apuntado por Dunbabin para los mosaicos del N. de África, donde la presencia 
de la crátera parece ser un elemento intrusivo (DUNBABIN, 1971, 52-65), en la musivaria hispana constituye un atributo frecuente del dios a partir del siglo II d.C, como se comprueba en los ejemplos citados, e incluso su mayor incidencia en Andalucía podría hacer pensar en una adaptación propia de los artesanos o talleres héticos (SAN NICOLÁS PEDRAZ, 1994a, 405-420).

Del oecus de la Casa de Tertulia en el Djem procede un panel musivo (Lám. 23), fechado $c a$. 200-220, con la representación de un cortejo dionisiaco, que pasa por debajo de un pórtico, en el que se ha figurado un carro de caja cuadrada abierto por delante, visto de perfil, tirado por un par de centauros, uno tocando la lira y el otro sosteniendo un gran rython sobre el hombro izquierdo y el pedum en la mano derecha, acompañados por un sátiro con tirso y una ménade tocando el tympanon. La rueda visible del carro es plana, sin indicación de los radios, como en el mosaico de Gerasa (vid. infra). La escena se desarrolla en un panel rectangular, el único que ha sobrevivido de los cuatro que rodeaban el medallón central decorado con el Triunfo dionisiaco, visto en perspectiva frontal, comentado anteriormente (vid. supra), por lo que es muy probable que el personaje que va sentado dentro del carro sea Hércules ebrio, como dice Foucher, y no Dionisos que ya ocupa el centro de la composición (FOUCHER, 1961, 49, lám. XXI a). Lo más interesante de la escena tunecina es que los atributos llevados por los centauros se repiten en los dos mosaicos hispanos, el rython sobre el hombro aparecía ya en el Triunfo astigitano, la lira en ambos y el pedum en Alcolea.

El mosaico dionisiaco de Gerasa, datado en época de Adriano o a comienzos de los Antoninos, se halla dividido entre el Pergamon Museum de Berlín (KRISELEIT, 1985, 17-21, núm. 4), la Embajada española en Damasco (BLAZQUEZ, LÓPEZ MONTEAGUDO, en prensa) y el Stark Museum of Art de Orange, en Texas (JOYCE, 1980, 307-325, fig. 1, lám. 103). De las escenas, representadas en varios frisos superpuestos, nos interesa la conservada en el último Museo (Lám. 24), puesto que en ella se ha representado un triunfo dionisiaco en el que los felinos, que tiran del carro del dios, han sido sustituidos por un par de centauros que marchan a paso lento hacia la derecha, uno con la cabeza vuelta al frente agitando el tympanon y el otro, de perfil, tocando el doble aulós. En el carro, que es de caja cuadrada y cuatro ruedas planas sin indicación de los radios, como en el mosaico de El Djem acabado de comentar, se ha figurado a Dionisos recostado acompañado de Ariadna, en posición inversa a la marcha, como ocurre en el mosaico hispano procedente de Fuente Álamo, también en la Bética (SAN NICOLÁS PEDRAZ, 1994, 1289-1304, lám. VII). Detrás del carro se ha representado a Baco niño cabalgando la pantera, seguido de una ménade y dos sátiros. Abren el cortejo Pan, montado en una cabra, y una ménade que levanta el tirso sobre su espalda con la mano izquierda y sostiene una antorcha en la derecha. 
Según Joyce, esta representación podría clasificarse en el tercero de los subgrupos de los sarcófagos dionisiacos establecidos por Matz, que se datan entre 130 y 170 (MATZ, 1968, II 3 a, 188 ss., núms. 83-93), y tiene un paralelo muy próximo en un medallón de bronce de Marco Aurelio (Lám. 16), fechado en 145-148 d.C, en el que el dios va sentado también en un carro tirado por dos centauros que tocan la lira y la doble flauta (LIMC III, "Dionysos/Bacchus", núm. 224a).

En la misma línea del pavimento dionisiaco de Gerasa se encuentra el mosaico de Sepphoris, de comienzos del siglo III, procedente de una gran casa descubierta al S. del teatro romano. Las escenas figuradas, todas de carácter dionisiaco, se desarrollan en catorce paneles dispuestos alrededor del emblema central, que es de forma rectangular, en el que se representa el concurso de bebida entre Hércules y Dionisos. Interesa aquí el panel del triunfo dionisiaco (Lám. 25), al que acompaña la inscripción en griego pompé, tirado por dos centauros, uno visto de perfil tocando el doble aulós, y el otro, con la cabeza vuelta hacia el dios, debía tocar la lira o el tympanon, a juzgar por la posición del trozo del brazo que queda. El dios va recostado, mirando de frente, en un carro de respaldo curvo y cuatro ruedas de ocho radios. Lleva manto que le cubre las piernas y la espalda, tirso en la mano derecha y copa en la izquierda. Adorna la cabeza con corona vegetal y nimbo. El ritmo pausado de la escena, en la que los centauros no galopan, sino que van al paso, aproxima esta representación a las figuradas en los pavimentos de El Djem, Gerasa, Nea Paphos y Sheikh Zouéde (WEISS, TALGAM, 1994, 231-237, fig. 4).

En el panel con representación del cortejo dionisiaco de la Casa de Aión en Nea Paphos (Lám. 26), se ha representado al dios sentado en el carro, que es de caja cuadrada y ruedas de ocho radios, tirado por un centauro viejo que lleva las flautas en ambas manos, y una centauresa tocando la lira con el plectrum. Abre el cortejo una ménade, portando el carcaj (?) sobre su hombro izquierdo, y lo cierra Trofeo, el viejo preceptor de Dionisos, que va montado sobre un asno y coronado de pámpanos, como Sueno. En un segundo plano se ve a una joven con el lyknon de los misterios sobre la cabeza - que en el mosaico de Acholla lo llevaba uno de los centauros - y la mano de una figura, que ha desaparecido, portando una antorcha. En primer plano un joven sátiro, debajo del que se ha escrito la palabra skirtos, nombre dado por Nonnos (dion. XIV 111,480,481) a un sátiro, ofrece la bandeja llena de frutos al dios. El mosaico se fecha en el segundo cuarto del siglo IV (DASZEWSKI, 1985, 24-27, láms. 3-4).

Dentro del grupo de mosaicos con representación del Triunfo de Dionisos en carro tirado por centauros, en perspectiva de perfil o de tres cuartos, el pavimento de Sheikh Zouéde constituye el ejemplo más tardío, ya que se data entre mediados del siglo IV y mediados del V, aglutinándose en él varias de las características iconográficas de épocas anteriores (Lám. 27). Las escenas mitológicas se reparten en dos registros 
superpuestos, asemejándose de esta forma a los mosaicos báquicos hispanos procedentes de Fuente Álamo y Baños de Valdearados (LÓPEZ MONTEAGUDO, 1998, en prensa). En la zona superior se ha figurado el mito de Fedra e Hipólito y, debajo, el thiasos báquico desarrollado linealmente en dos frisos sin línea divisoria. El cortejo, que precede al carro del dios, lo abren en el extremo inferior derecho una ménade danzando, con tirso en la mano derecha y tympanon en la izquierda, y un sátiro que toca el cuerno con la mano izquierda y lleva pedum en la mano derecha. Sigue Pan danzando y tocando los crótalos con su mano izquierda levantada, mientras que con la derecha ase un racimo de uvas, vuelve la cabeza hacia el grupo siguiente, formado por Hércules (Herakles) ebrio apoyado en un sátiro, del que le separa un leopardo agarrando una crátera. El cortejo continúa en la parte de arriba, donde se ha figurado, de derecha a izquierda, un grupo formado por ménade y sátiro (skirtos) danzando y tocando los címbalos y los crótalos. Sigue Papposilenos montado en el asno y, a continuación, el carro de Dionisos tirado por un centauro, que se vuelve hacia el dios tocando el aulós, y una cetauresa que tañe la lira, como en Nea Paphos, guiados por un Eros que sostiene en sus manos las riendas. Dionisos, identificado por su nombre lo mismo que el Eros y acompañado de la palabra thelethé, que hace referencia a los misterios dionisiacos, va sentado en el carro, del que solo se ven dos ruedas de ocho radios y el tiro sobre el que se apoya el Eros. Toca su cabeza con dos racimos de uvas que caen sobre las sienes, como en el pavimento itálico de Tenuta de Fiorano \{vid. supra) y en los citados mosaicos hispanos de Fuente Álamo y Baños de Valdearados, y va vestido con túnica de manga larga y manto drapeado que le cubre las piernas, dejando ver los pies por debajo. Lleva tirso en la mano izquierda y crátera vertiendo el líquido en la derecha, hacia la que corre un segundo leopardo (OVADIAH, GÓMEZ DE SILVA, MUCZNIK, 1991, 181-191 láms. 22-25).

$\mathrm{Al}$ igual que ocurre en la escena astigitana y en otros triunfos báquicos vistos en perspectiva frontal, el Triunfo báquico de Alcolea, en la variante de perfil o de tres cuartos, encuentra muchas similitudes tanto iconográficas como de perspectiva, en varios Triunfos de Neptuno, mostrando una vez más la contaminación existente entre ambas representaciones. Baste recordar los mosaicos hispanos del Triunfo de Neptuno procedentes de Itálica y Sagunto, los norteafricanos de Timgad, Thuburbo Maius, Uthina y Sousse (Lám. 28), o los itálicos de Otricoli, Palermo y Aquileia (NEIRA JIMÉNEZ, 1996, 555-576, láms. III, IV, VII, VIII, X y XI). Como en los casos de perspectiva frontal, tampoco los triunfos de Neptuno, vistos de perfil o de tres cuartos, son ajenos a la presencia de tritones guiando a los hipocampos que tiran del carro del dios. Así aparecen en dos mosaicos norteafricanos del siglo IV, procedentes de Djemila y Sidi Ghrib, con la representación del Triunfo de Neptuno y Anfitrite, aunque en ninguno de ellos los caballos e hipocampos han sido sustituidos por tritones o centauros marinos, como ocurría en el citado mosaico de Misis-Mopsuhestia (vid. 
supra), particularidad que, sin embargo, sí se documenta en el mosaico pompeyano de la Casa del Granduca de Toscana, donde los tritones se han figurado tirando directamente del carro de Neptuno y Anfítrite (NEIRA JIMÉNEZ, 1996, 564-565, nota 29; ID., 1996a, en prensa).

La zona central del pavimento de Djemila, donde se supone que figuraba el Triunfo de Neptuno y de Anfítrite, falta casi en su totalidad. Solo se ha conservado parte del dios, identificable por el tridente y el manto arqueado sobre la cabeza, y un tritón visto de tres cuartos, casi de frente, y la cara de perfil hacia la derecha, guiando con la mano derecha las bridas de un hipocampo que tira del carro triunfal, mientras que con la izquierda levanta un cesto o una crátera sobre el hombro. A juzgar por la simetría que guardan las dos nereidas y los dos putti, situados en los extremos de la escena flanqueando al grupo central, podría pensarse que se trata de un ejemplo más de thiasos marino visto en perspectiva frontal (BLANCHARD-LEMEE, 1975, 114119, láms. XXIX y XXXb).

El otro Triunfo de Neptuno y Anfítrite, procedente del frigidarium de las termas del Thiasos marino de Sidi Ghrib (Lám. 29), ocupa el registro superior de los varios que, sin delimitación concreta, se superponen en el campo musivo. En el registro superior se ha representado una variante del triunfo de Neptuno, ya que la pareja divina, aureolada por el manto del dios, aparece de frente, en amoroso abrazo, sentada directamente sobre las espirales de un caballo marino guiado por un tritón visto de espaldas, que vuelve la cabeza hacia el grupo (ENNABLI, 1986, 34-35, lám. VII). El modelo se documenta ya en una pintura pompeyana (Lám. 30), donde la pareja divina aparece también sentada directamente sobre un tritón, que marcha hacia la izquierda sujetando con ambas manos un ánfora sobre su hombro izquierdo (LIMC VE, "Poseidon/Neptunus", núm. 94), como en los Triunfos báquicos de Corinto y Dión (vid. supra).

El mosaico pompeyano de la Casa del Granduca de Toscana (Lám. 31), fechado en 40 a.C, muestra a Neptuno y Anfítrite, acompañados de un amorcillo, sentados en un carro de alto respaldo y, curiosamente puesto que va sobre el mar, con dos ruedas de seis radios, que se dirige hacia la derecha tirado por dos tritones, uno vuelto con los brazos levantados tocando el doble aulós, y el otro visto de perfil (LIMC VII, "Poseidon/ Neptunus", núm. 97). El tema se repite en el relieve marmóreo de la Glyptoteca de Munich (Lám. 32), fechado según E. Simón en 97 o 70 a.C, aunque en esta ocasión el cortejo se dirige hacia la izquierda (LIMC VII, "Poseidon/Neptunus", núm. 119).

Esta contaminación iconográfica entre el thiasos marino y el dionisiaco es un hecho generalizado en el mundo romano, como se comprueba en los tritones de la Bética (TORRES CARRO, 1990, 110-114) y sobre todo en Italia, en el mosaico de las Termas de Neptuno o en el de la domus dei dioscuri, en Ostia (BECATTI, 1961, 
láms. CXXXI y CLIII), y se produce también en la musivaria del N. de África en pavimentos procedentes de Acholla (PICARD, 1968, 138-146, figs. 25-26 y 28), Utica (CMTl 2, 1974, núm. 205, lám. XXXV) y El Djem, (FOUCHER, 1962, lám. XLVI; 1994, 70-80, láms. XI-XII). En todos ellos los tritones se realizan con unos rasgos faciales muy próximos a los de los sátiros del cortejo dionisiaco, que se subrayan con los típicos atributos báquicos como son los cuernos, la nebris, el pedum y la antorcha. Pero la contaminación entre el thiasos marino y el dionisiaco no se reduce únicamente a los detalles iconográficos, sino que ambos temas incluso se combinan en un mismo pavimento, como ocurre en los mosaicos tunecinos de El Djem (FOUCHER, 1994, 70-80, láms. VIII-XIV) y de las termas de Trajano en Acholla \{vid. supra), donde los tritones y las nereidas se hallan incluidos en un thiasos báquico, o forman parte de un mismo programa iconográfico, como ocurre en la Casa del Triunfo de Dionisos en Antioquía, decorada con los dos tipos de thiasos (LEVI, 1947, 91-104, láms. XVI c-d), por citar solo unos ejemplos.

En todo caso, lo más notable de los dos mosaicos hispanos es que se trata de una iconografía del Triunfo de Dionisos que es única, por el momento, en la musivaria hispana, ya que de las dieciséis representaciones conocidas hasta el momento, solo en estas dos los felinos han sido sustituidos por centauros, siendo además el mosaico de Ecija el único ejemplo hispano de perspectiva frontal. Fuera de Hispania la sustitución de los felinos por los centauros, que tiran directamente del carro del dios, se constata solamente en siete pavimentos y nunca en perspectiva frontal donde, a diferencia de otros soportes, los centauros siempre figuran guiando a los animales. Según Foucher, la iconografía del carro de Dionisos tirado por centauros gozó de un gran favor en la primera mitad del siglo II, tanto en la musivaria como en los sarcófagos, cuya ejecución remonta a los años 135-140. Continúa diciendo este investigador que el modelo que ha inspirado a los artistas debió ser el grupo firmado por Aristeas y Papias, procedente de la escuela de Afrodisias de Caria, que mostraba ya a dos centauros, uno viejo y otro joven, sin olvidar los de la villa adriánea de Tívoli y la descripción hecha por Luciano (Zeux. 4 ss.) de una pintura de Zeuxis que representaba la theleia hippocentauros, y, por supuesto, la relación del tema con las tendencias de la época que asimilaban, sobre todo a partir de la guerra pártica, a Trajano con el dios evergeta, dominador del Oriente, guerrero victorioso contra la barbarie, representada por esos seres brutales semi humanos, semi animales, que son los centauros, y propagador de la civilización y de la virtus romana que dispensa la Felicitas (FOUCHER, 1975, 57).

En ninguno de los dos casos hispanos los centauros aparecen tocando el doble aulós, como es habitual en este tipo de representaciones, ya sea en mosaicos, sarcófagos, relieves, monedas o telas, y aunque sí llevan otros atributos frecuentes, 
como son el pedum, el tympanon, la lira y el rython, en el caso de la lira, que constituye uno de los instrumentos más característicos de los centauros, no lo hacen en la forma habitual, sino que la cargan sobre el hombro, a la manera de los kantharoi en los mosaicos de Corinto y de Dión. Refiriéndose a los sarcófagos, Turcan escribe que los objetos portados por los centauros, como son el tirso, el lyknon cubierto con el velo, el ramo de pino o el cuerno de la abundancia, no solo son atributos de la encantación orgiástica o de la embriaguez, sino también de la iniciación o de la perennidad; hacia 189-190 los centauros aparecen provistos de una pequeña ánfora (?) o de un cántaro y ya en el III, concretamente entre 230 y 240 , se constata el motivo del centauro vertiendo el vino en un cántaro. Según este autor, los distintos gestamina hacen de los centauros "les "télestes" de Bacchus, les consécrateurs d'Ariadna ou d'Hercule" (TURCAN, 1966, 505-509). La presencia de estos seres en los mosaicos procedentes de ambientes no funerarios plantea la cuestión de su simbolismo en torno a la prosperidad y al bienestar, como las fuerzas salvajes domadas y sometidas al yugo de $\mathrm{Baco}^{6}$. Pero en Alcolea el triunfo báquico forma parte, además, de un programa iconográfico en el que también aparece la Loba y los Gemelos, alegoría romana de la eternidad. Esta conjunción, documentada igualmente en un sarcófago de Ostia (SCHAUENBURG, 1966, 277, figs. 16-17), proporciona a los centauros un carácter al mismo tiempo de inmortalidad.

\section{BIBLIOGRAFÍA}

BARATTE, F. (1973): "Le tapis géométrique du triomphe de Neptune de Constantine", MEFRA, 85, París, 313-334.

BATTISTELLI, E, DELI, A. (1983): Immagine di Fano romana, Fano.

BECATTI, G. (1961): Scavi di Ostia. IV, Roma.

BLAKE, M.E. (1936): "Roman Mosaics of the Second Century in Italy", 'MAAR XIII, Roma, 67-214

BLANCHARD-LEMEE, M. (1975): Maisons a mosaíques du Quartier Central de Djemila (Cuicul), París.

BLAZQUEZ, J.M. (1980): "Los mosaicos romanos de Torre de Palma (Monforte, Portugal)", AespA. 53, Madrid, 123-161.

\footnotetext{
${ }^{6}$ Con el mismo simbolismo aparecen cuatro centauros tirando del carro de Hércules, guiados por una nike, en cerámica ática de Cirene, de hacia 410 a.C. (LIMC VIII, "Kentauroi et Kentaurides", núm. 299).
} 
BLAZQUEZ, J.M. ET ALII (1986): "Hallazgo de mosaicos romanos en Beas de Segura (Jaén)", AEspA., 59, Madrid, 227-232.

BLAZQUEZ, J.M., LÓPEZ MONTEAGUDO, G. (en prensa): "Mythologische Darstellungen, Neldenlegenge und Abbildungen von Schrifstellern auf Mosaiken der Keiserzeit, aus Syrein, Palästina, Arabien, Zypern, Griechenland, Kleinasien und Armenien", en ANRW, Berlín.

BUDDE, L. (1969 y 1972): Antike Mosaiken in Kilikien, I y II, Recklinghausen.

DASZEWSKI, V.A. (1985): Dionysos der Erloser, Mainz.

DASZEWSKI, V.A., MICHAELIDES, D. (1989): Guide des mosdiques de Paphos, Nicosia.

DENEAUVE, J. (1969): Lampes de Carthage, París.

DONDERER, M. (1988): "Dionysos und Ptolemaios Soter ais Meleager. Zwei Gamalde des Antiphilos", en Festschrift G. Wirth, II, Amsterdam, 781-799.

DUNBABIN, K.M.D. (1971): "The Triumph of Dionysus on Mosaics in North África", PBSR, XXXIX, London, 52-65.

ELIADES, G.S. (1986): La Maison de Dionysos. La villa des mosdiques de la Nouvelle Paphos, Paphos.

ENNABLI, A. (1986): "Les thermes du thiase marin de Sidi Ghrib", MonPiot 67-68, París, 1-59.

FERNANDEZ GALIANO, D. (1984): "El Triunfo de Dioniso en mosaicos hispanorromanos", AEspA. 57, Madrid, 97-120.

FERNANDEZ GÓMEZ, F. (1997): "Excavaciones de urgencia del Museo Arqueológico de Sevilla en la ciudad de Ecija", Bol. de la Real Academia de Ciencias, Bellas Artes y Buenas Letras "Vélez de Guevara", 1, Ecija, 15-91.

FERNANDEZ GÓMEZ, F. (1998): "Nuevos mosaicos romanos en Ecija (Sevilla)", Rev. de Arq., núm. 207, Madrid, 32-41.

FOUCHER, L. (1953): "Un hypogée romain á Sousse", Karthago IV, París, 83-96.

FOUCHER, L. (1961): Découvertes archéologiques á Thysdrus en 1960, Tunis.

FOUCHER, L. (1962): Découvertes archéologiques á Thysdrus en 1961, Tunis.

FOUCHER, L. (1975): "Le char de Dionysos", en II CMGR, París, 55-61.

FOUCHER, L. (1994): "Une mosaíque de Thysdrus", en Mélanges a la mémoire de Marcel Le Glay, coll. Latomus 226, Bruxelles, 70-80. 
GARCÍA Y BELLIDO, A. (1965): "Los mosaicos de Alcolea (Córdoba)", BRAH 156, Madrid, 7-19.

GERMAIN, S. (1969): Les mosaiques de Timgad, París.

GOZLAN, S. (1992): La maison du triumphe de Neptune á Acholla (Botria, Tunisie). I. Les Mosaiques, Roma.

JOYCE, H. (1980): "A mosaic from Gerasa in Orange, Texas, and Berlin", RM. 87, Mainz, 307-325.

KANKELEIT, A. (1994): "Die kaiserzeitlichen Mosaiken von Olympia. Eine Bestandsaufhahme", en VI CIMA (Guadalajara-Mérida 1990), Guadalajara, 135-147.

KESSIAKOVA, E. (1994): "Nouveaux pavements de mosaíque á Philippopolis", en CMGR IV, Tréves 1984, París, 165-170.

KRISELEIT, I. (1985): Antike Mosaiken, Berlin.

LENZEN, V.F. (1960): The Triumph of Dionisos on the Textiles of late Antique Egypt, Berkeley-Los Angeles.

LEVI, D. (1947): Antioc Mosaic Pavements, Princeton.

LÓPEZ MONTEAGUDO, G. (1991): "El mosaico de las estaciones de Córdoba", TP., 48, Madrid, 365-372.

LÓPEZ MONTEAGUDO, G. (1997): "Los mosaicos romanos de Ecija (Sevilla). Particularidades iconográficas y estilísticas", VIII CIMA (Lausanne 1997), en prensa.

LÓPEZ MONTEAGUDO, G. (1998): "The Triumph of Dionysus on two Mosaics in Spain", Assaph, 4, Tel Aviv, en prensa.

LÓPEZ MONTEAGUDO, G. ET ALII (1996): "Recientes hallazgos de mosaicos romanos figurados en Hispania", en VII CIMA (Tunis 1996), en prensa.

MASSIGLI, R. (1912): Musée de Sfax, Paris.

MATZ, F. (1968-1975): Die dionisyschen Sarkophage, I-IV, Berlin.

MEZQUIRIZ, M.A. (1987): "Mosaico báquico hallado en Ándelos", Rev. de Arq., núm. 77, Madrid, 59-61.

MICHAELIDES, D. (1987): Cypriot Mosaics, Nicosia.

NEIRA JIMÉNEZ, M.L. (1996): "La tipología del carro en los mosaicos romanos del triunfo de Neptuno, en L'África Romana, Atti dell'Xl convegno di studio (Cartagine 1994), Sassari, 555-576. 
NEIRA JIMÉNEZ, M.L. (1996a): "Un type de Néreide sur des mosaíques romaines d'Afrique du Nord", en VII Colloque International: Histoire et Archéologie de l"Afrique du Nord (Nice 1996), en prensa.

NICOLAU, K. (1984): "Three New Mosaics at Paphos, Cyprus", en III CIMA (Ravenna 1980), Ravenna, 219-225.

OVADIAH, A., GÓMEZ DE SILVA, C, MUCZNIK, S. (1991): "The Mosaic Pavements of Sheikh Zouéde in Northern Sinai", en Tesseare. Festschrift J. Engemann, $J A C, 18$, Münster, 181-191.

PANDERMALIS, D. (1997): Dion. Site archéologique et Musée, Athénes.

PARLASCA, K. (1959): Die rómischen Mosaiken in Deutschland, Berlin.

PARLASCA, K. (1983): "Neues zu den Mosaiken von Edessa und Seleukeia am Euphrat", en III CIMA (Ravenna 1980), Ravenna, 227-234.

PARRISH, D. (1995): "A Mythological Theme in the Decoration of Late Román Dining Rooms: Dionysos and his Circle", RA., 2/95, París, 307-332.

PICARD, G. (1959): "Les Mosaíques d'Acholla", Etudes d Archéologie Classique, II, 78-95.

PICARD, G. (1968): "Les thermes du Thiase marin a Acholla", AntAfr. 2, París, 95-151. SALIES, G. (1974) "Untersuchungen zu den geometrischen Gliederungsschemata romischer Mosaiken", BJ. 174, Bonn, 1-178.

SALOMONSON, J.W. (1965): La mosaique aux chavaux de VAntiquarium de Carthage, La Haye.

SAN NICOLÁS PEDRAZ, M.P. (1994): "Mosaicos y espacio en la villa romana de Fuente Álamo", en L'África Romana, Atti dell'X convegno di studio (Oristano 1992), Sassari, 1289-1304.

SAN NICOLÁS PEDRAZ, M.P. (1994a): "La iconografía de Dionisos y los indios en la musivaria romana. Origen y pervivencia", en Antigüedad y Cristianismo XI (=Congreso Internacional sobre La tradición en la Antigüedad Tardía, Madrid 1993), Murcia, 405-420.

SCHAUENBURG, K. (1966): "Die Lupa Romana ais sepulkrales Motiv", Jdl 81, Berlin, 261-309.

TORRES CARRO, M. (1990): "Iconografía marina", en Mosaicos romanos. Estudios sobre iconografía (= Alberto Balil in memoriam), Guadalajara, 107-134. 
TURCAN, R. (1966): Les sarcophages romaines a représentations dionysiaques, París.

WEINBERG, S.S., (1960): Corinth I,V, Princeton, 113-122.

WEISS, Z., TALGAM, R. (1994): "The Dionysiac mosaic floor of Sepphoris", en VI CIMA (Guadalajara-Mérida 1990), Guadalajara, 231-237. 

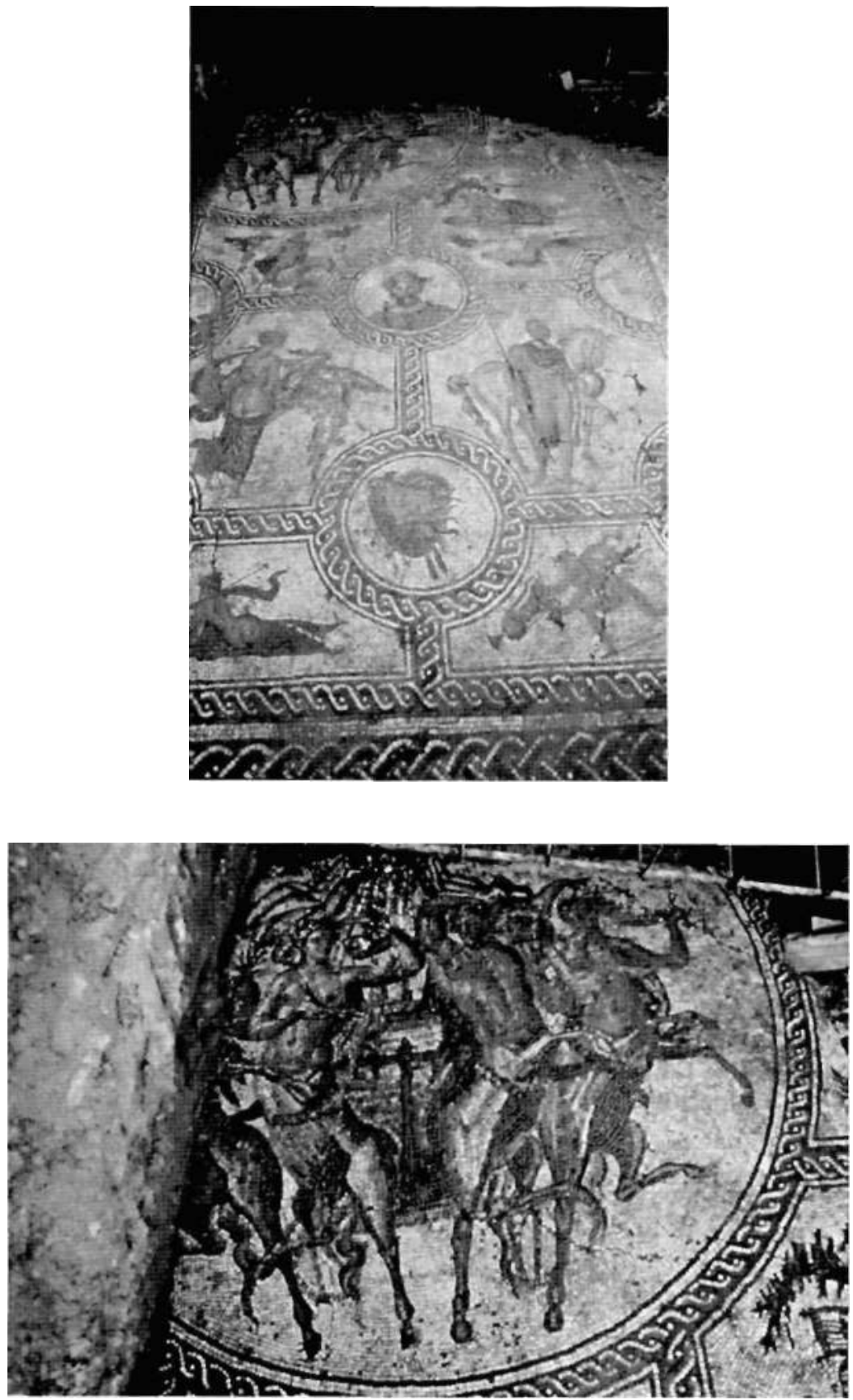

Lám. 1.1. Mosaico de Ecija. 2. Detalle del emblema. Fotos cortesía F. Fernández. 

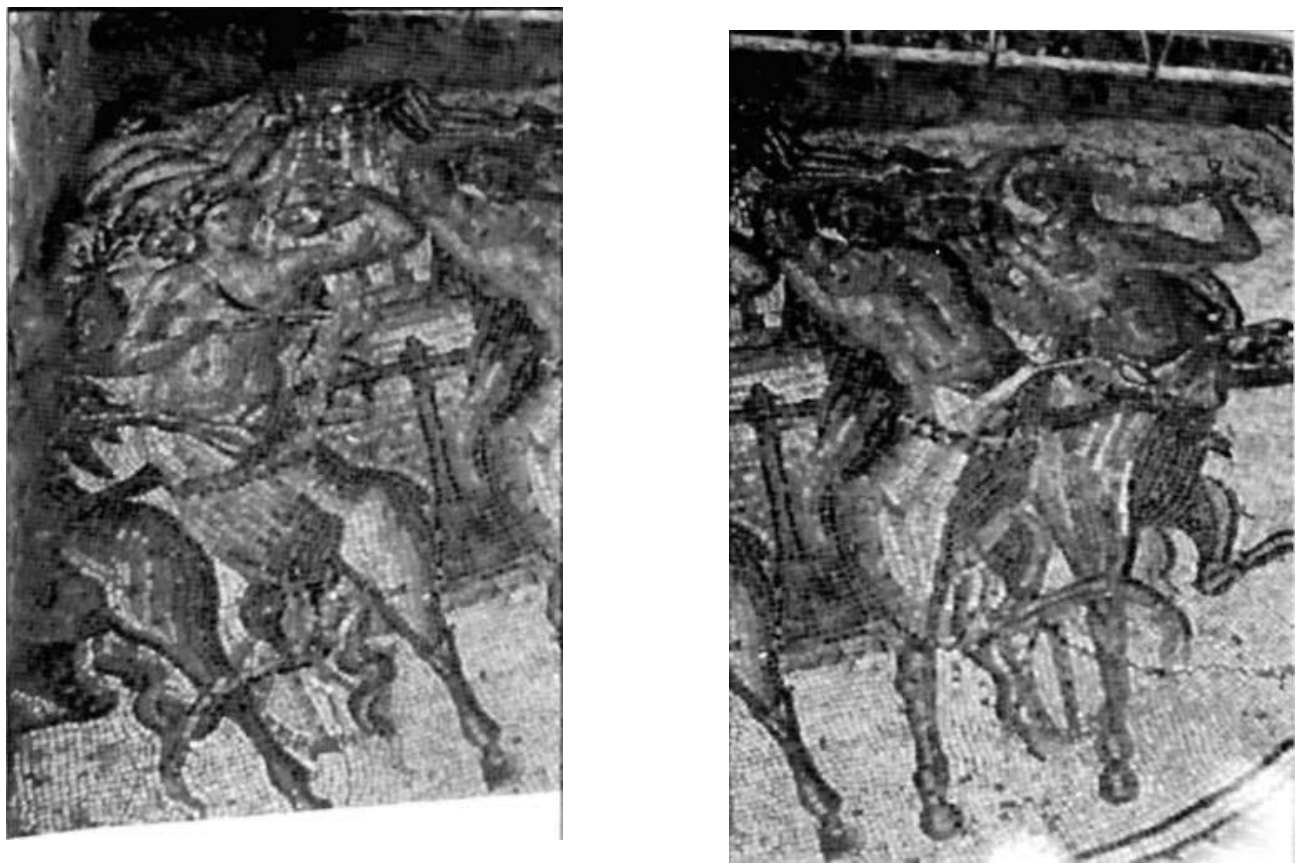

Lám. 2. Mosaico de Ecija. Detalles del emblema. Fotos cortesía F. Luna.

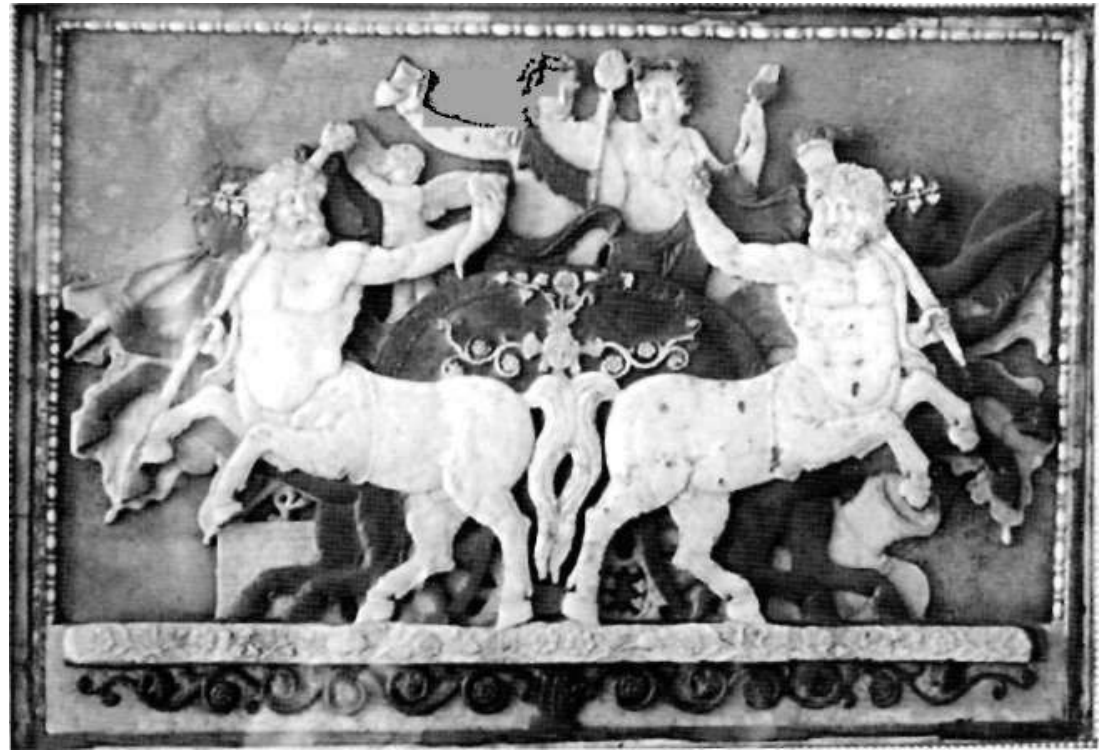

Lám. 3. Camafeo del Louvre. Foto M.L. Neira 


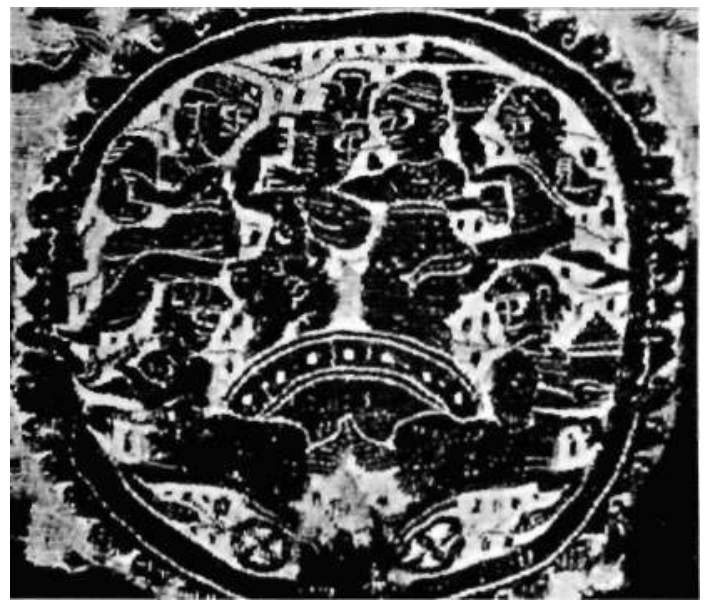

Lám. 4. Tela copta del Victoria and Albert Museum. \{LIMC III, "Dionysos in per. or.", núm. 135).

Lám. 5. Mosaico de Corinto. Según S.S. Weinberg.
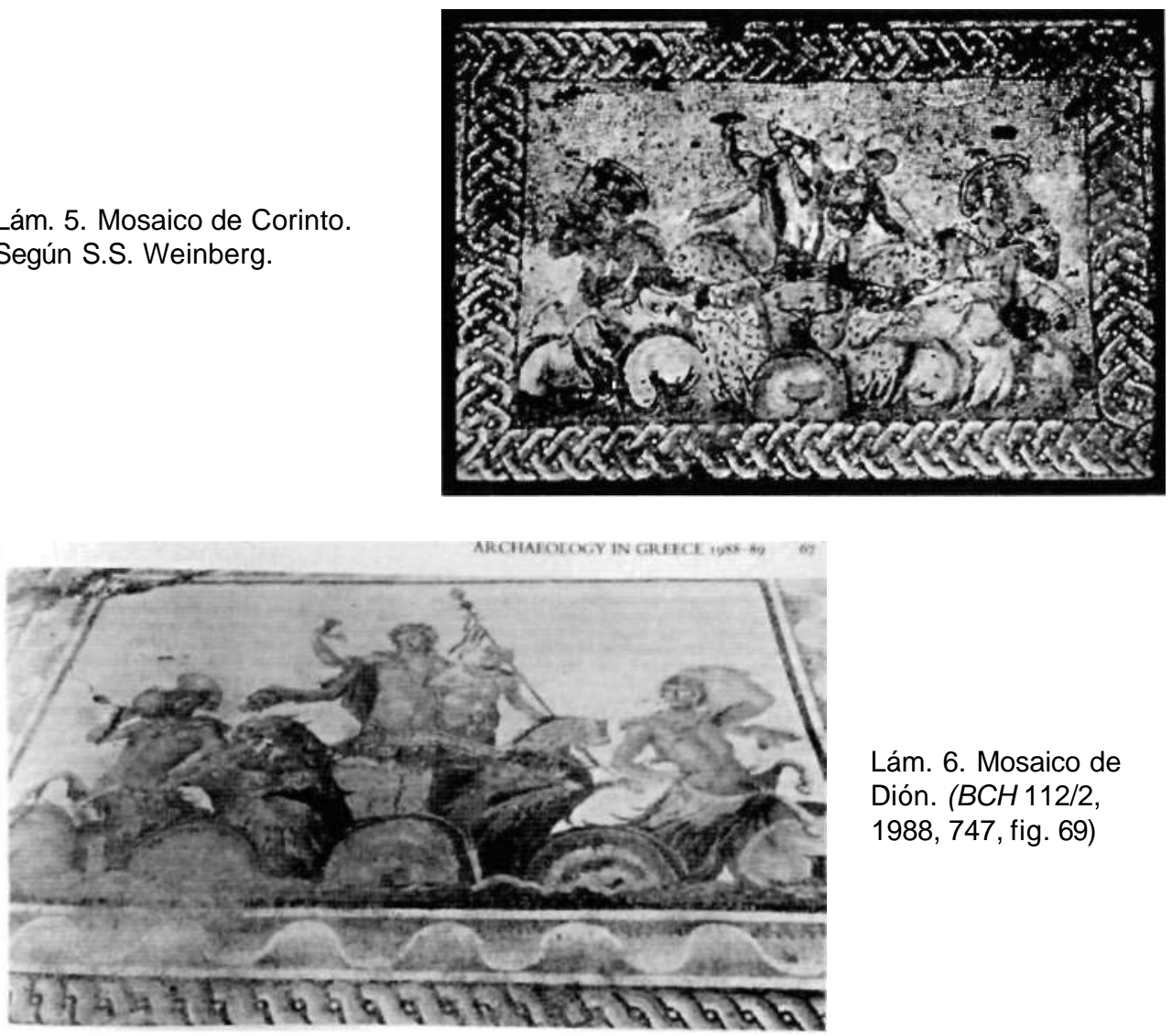

Lám. 6. Mosaico de Dión. (BCH 112/2, 1988, 747, fig. 69) 
Lám. 7. Mosaico de El Djem. Foto G. López Monteagudo.
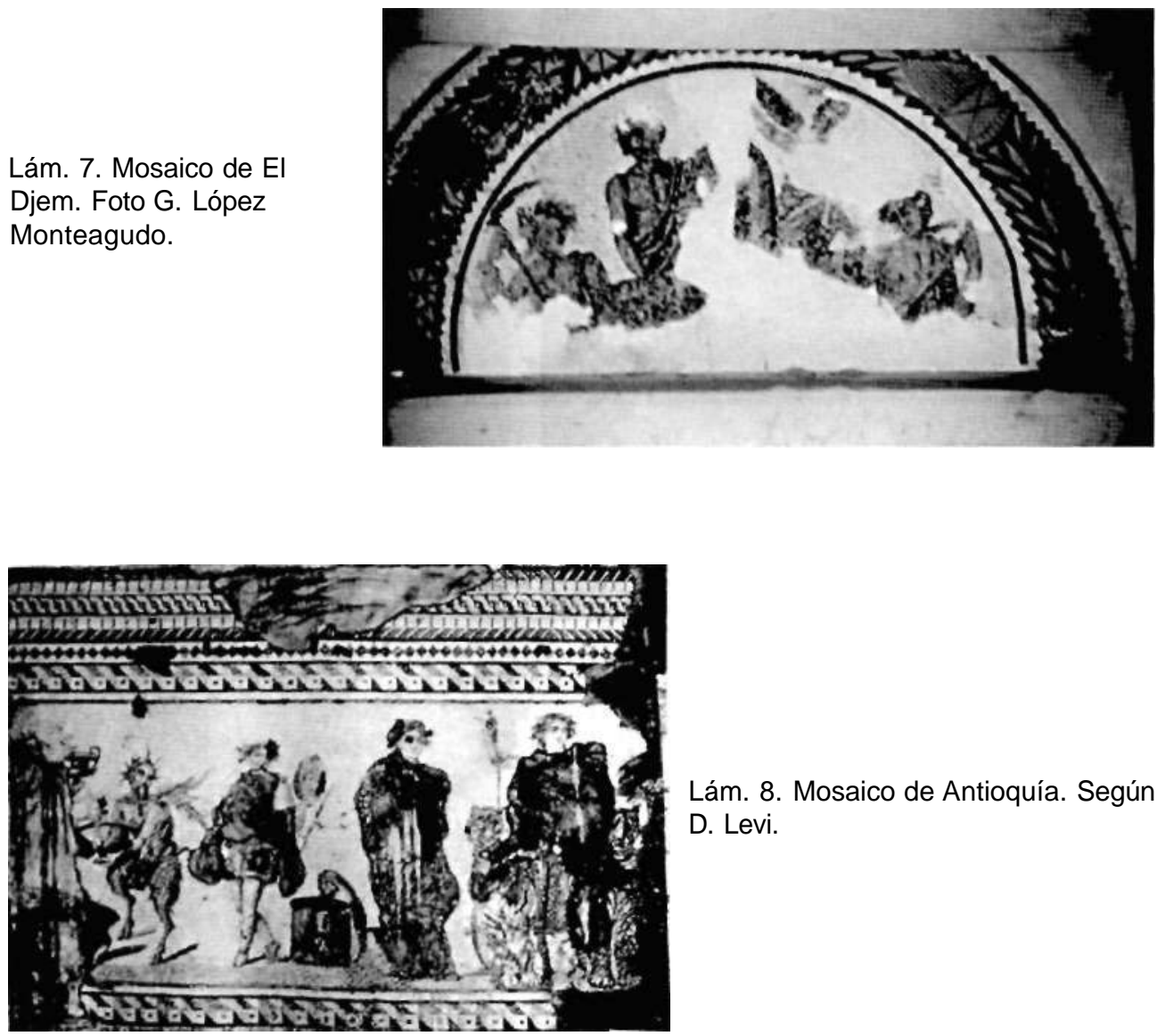

Lám. 8. Mosaico de Antioquía. Según D. Levi.

Lám. 9. Estuco de Sousse. Según L. Foucher.

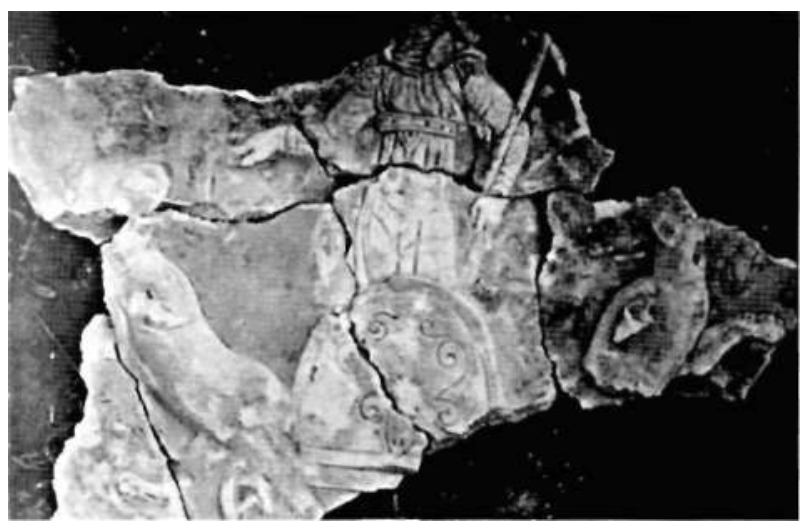




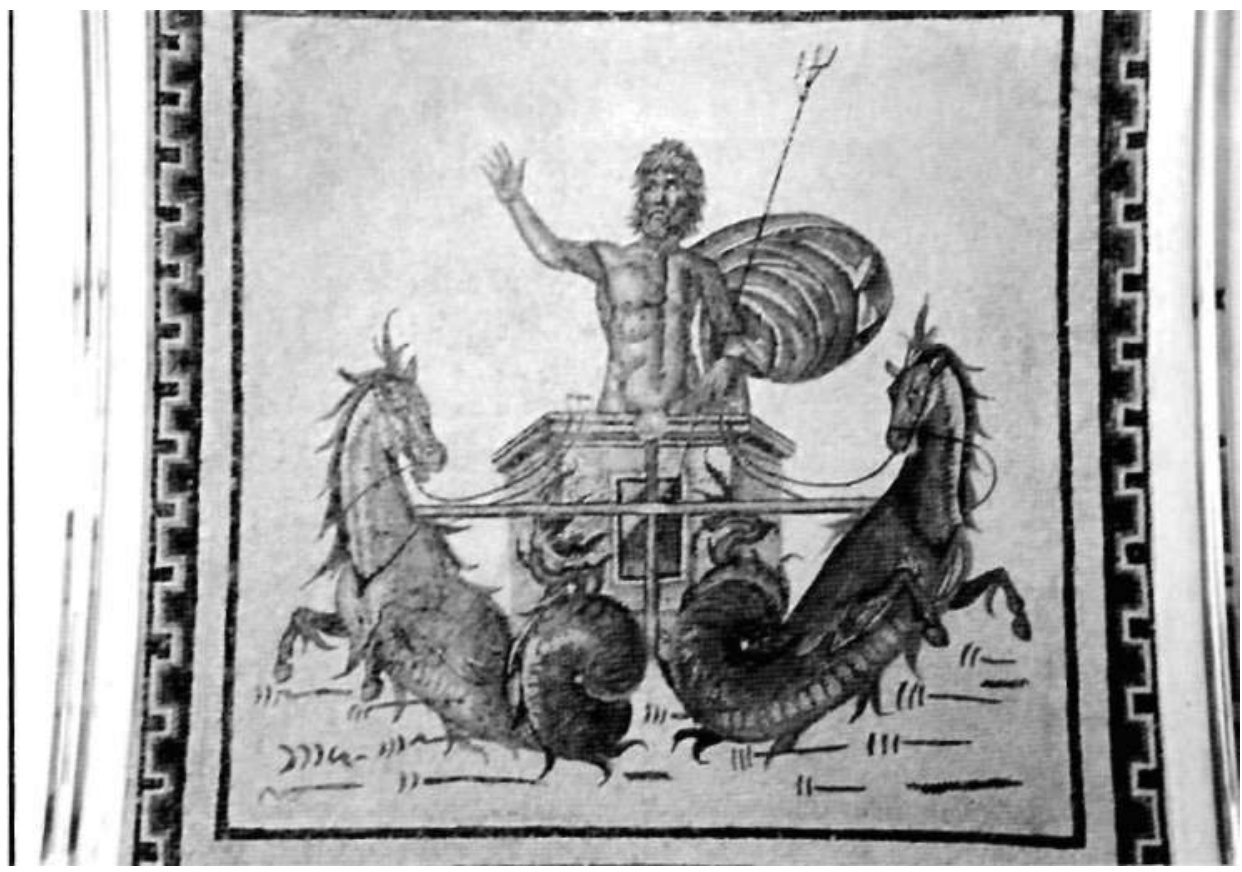

Lám. 10. Mosaico de Acholla. Foto G. López Monteagudo

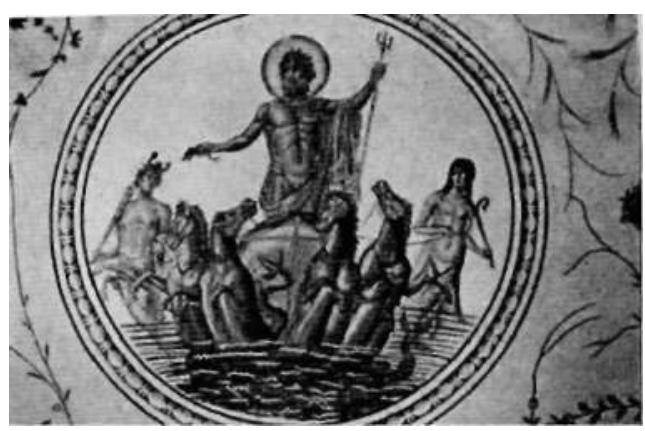

Lám. 11. Mosaico de La Chebba. Foto M.L. Neira

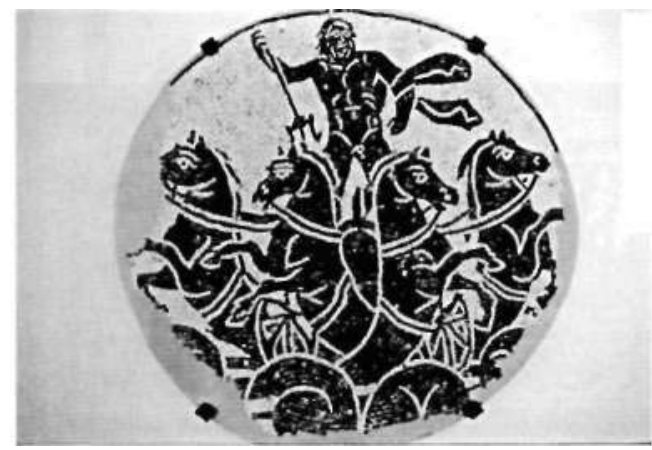

Lám. 12. Mosaico de Fano. Foto cortesía M.L. Neira 


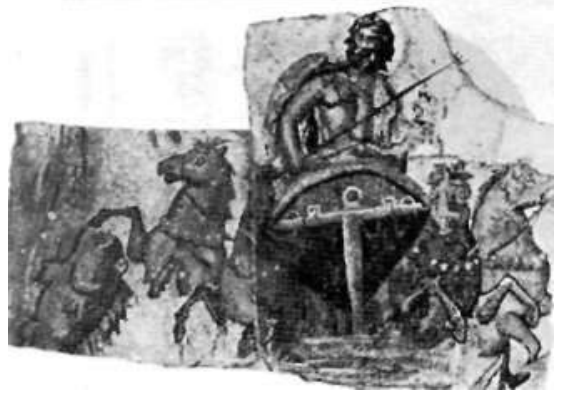

Lám. 13. Mosaico de Seleukia. Según K. Parlasca.

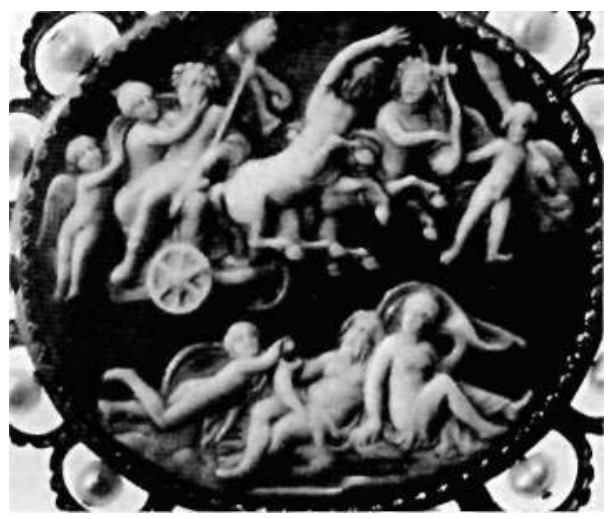

Lám. 15. Camafeo del Cabinet des Médailles de Paris. (LIMC III "Bacchus", núm. 215).

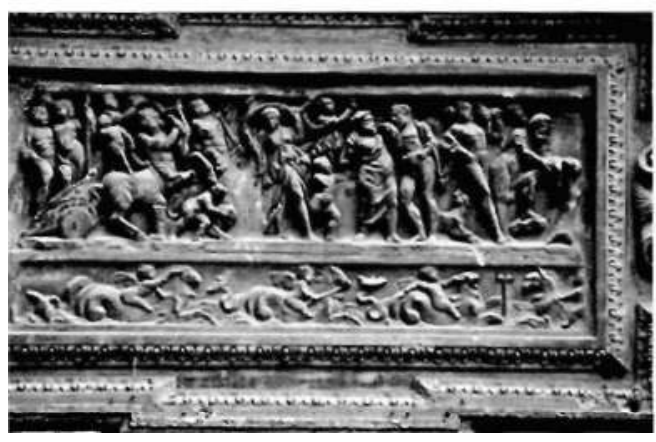

Lám. 17. Sarcófago de Roma, Palazzo Mattei. Foto G. López Monteagudo

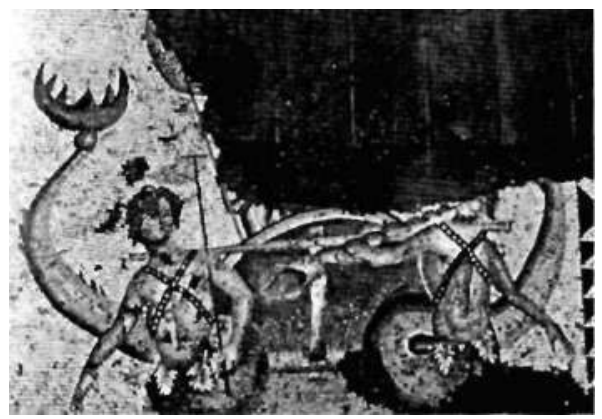

Lám. 14. Mosaico de Misis Mopsuhestia. Según L. Budde.

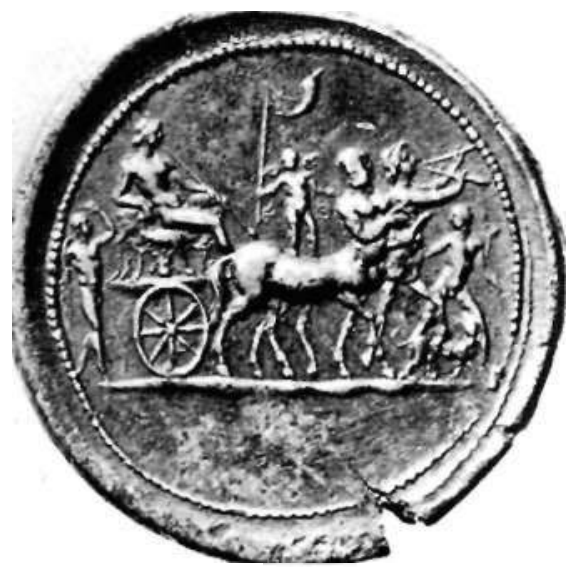

Lám. 16. Medallón de Marco Aurelio, Roma. (LIMC III "Bacchus", núm. 224a).

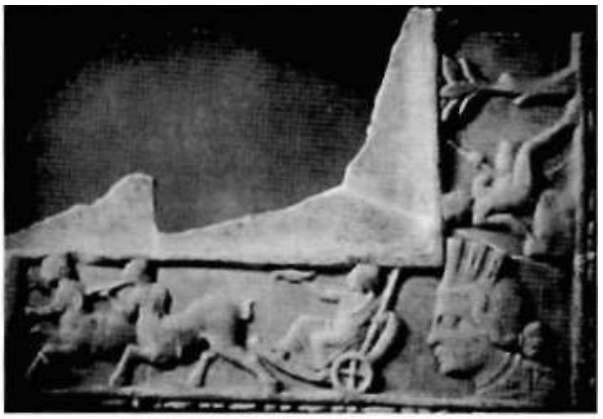

Lám. 18. Mesa-sigma del

Kunsthistorlsches Museum de Viena. Según D. Parrish. 
SOBRE UNA PARTICULAR ICONOGRAFÍA DEL TRIUNFO DE BACO...

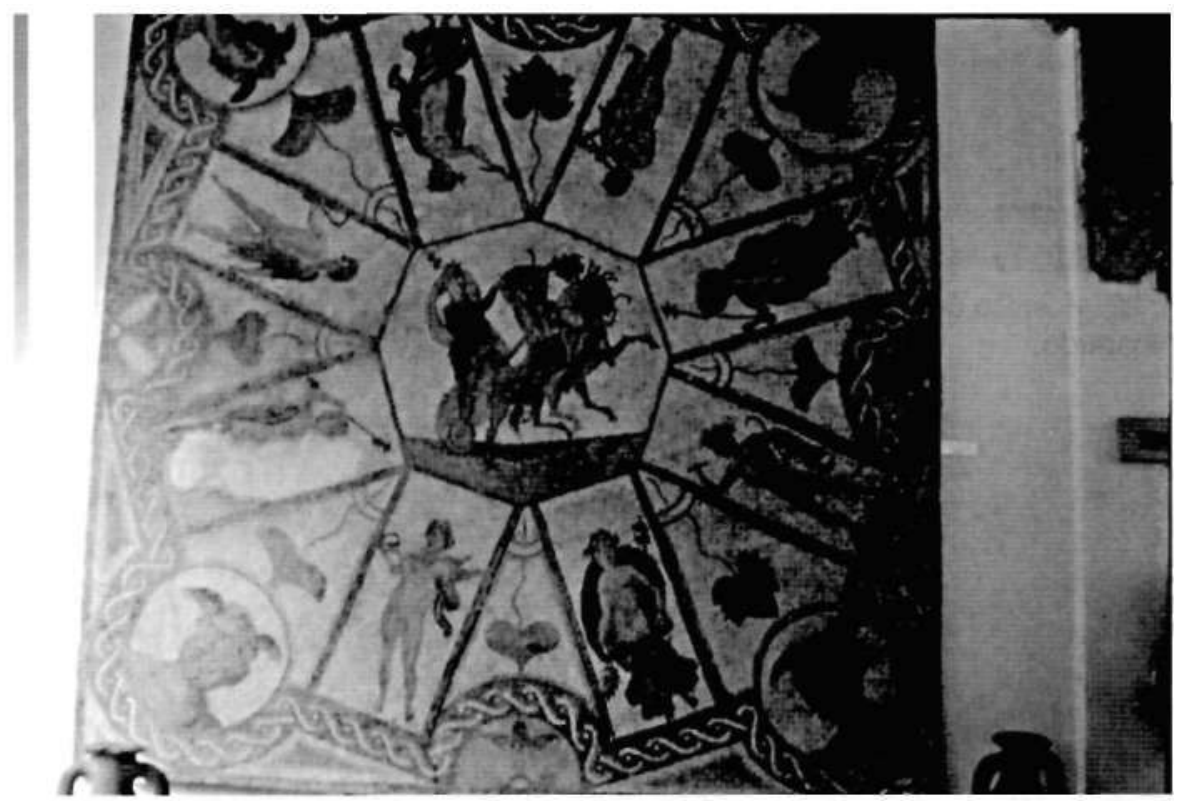

Lám. 19. Mosaico de Alcolea. Foto G. López Monteagudo.

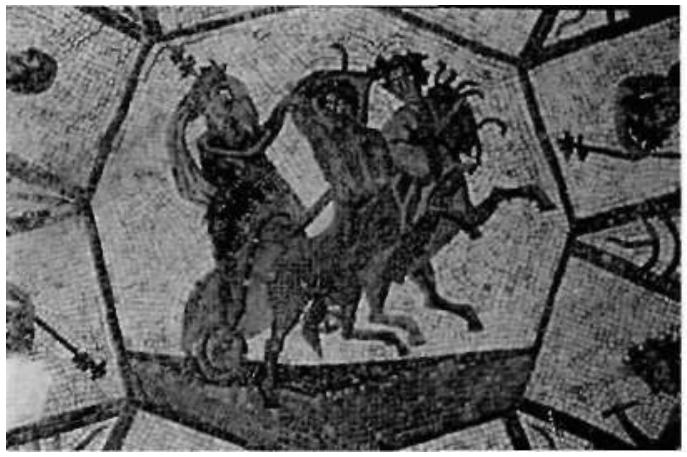

Lám. 20. Mosaico de Alcolea. Detalle del octógono central. Foto G. López Monteagudo.

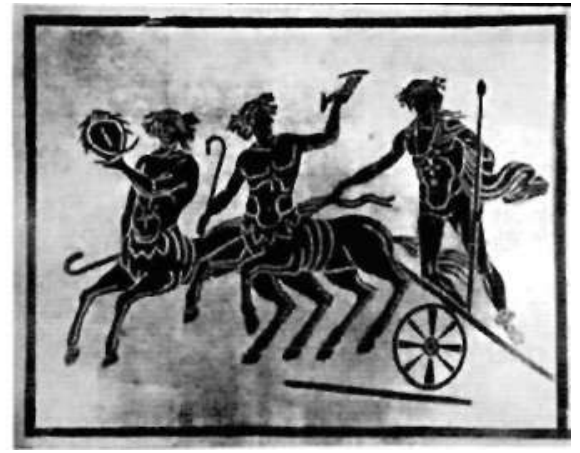

Lám. 21. Mosaico de Tenuta de Fiorano. Según E. Blake. 


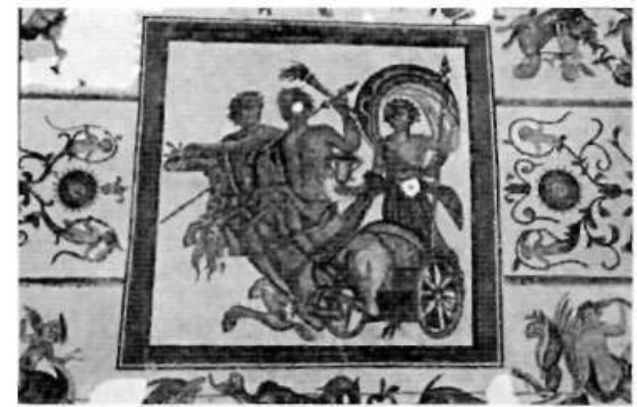

Lám. 22. Mosaico de Acholla. Foto G. López Monteagudo.

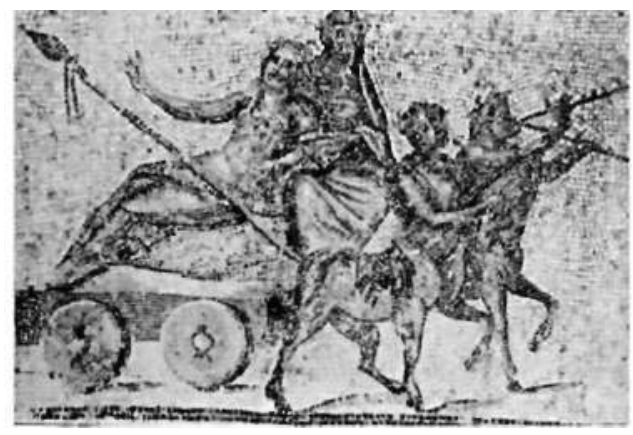

Lám. 24. Mosaico de Gerasa. Según H. Joyce Lám. 25. Mosaico de Sepphoris. Según Z. Weiss, R. Talgam.

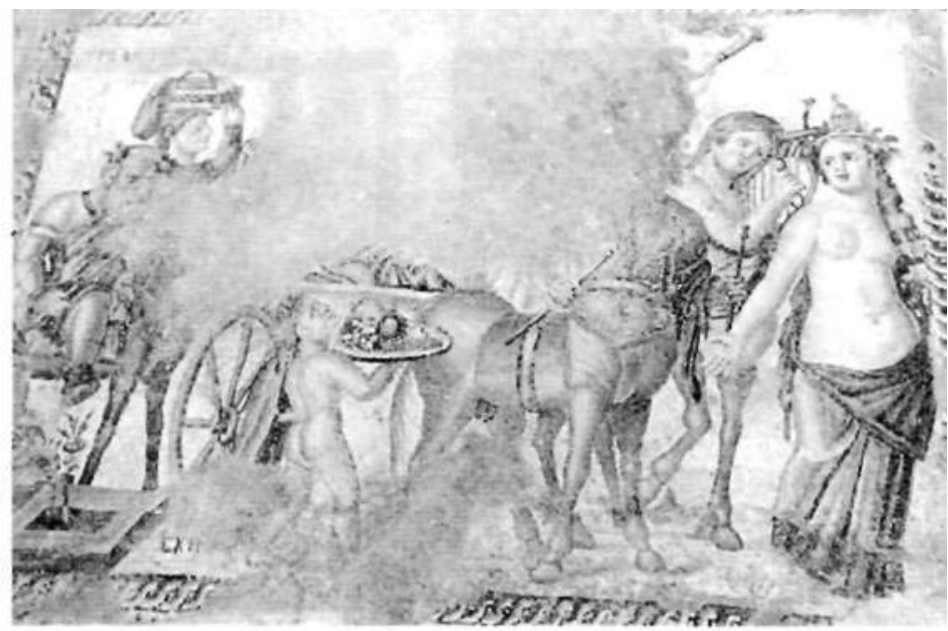

Lám. 26. Mosaico de Nea Paphos. Foto G. López Monteagudo. 


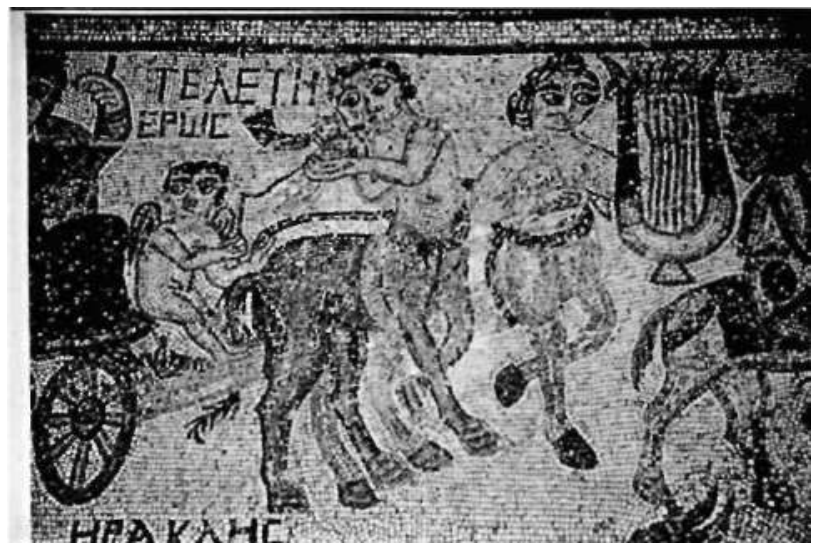

Lám. 27. Mosaico de Sheikh Zouéde. Según A. Ovadiah.

Lám. 28. Mosaico de

Sousse. Foto G. López Monteagudo.
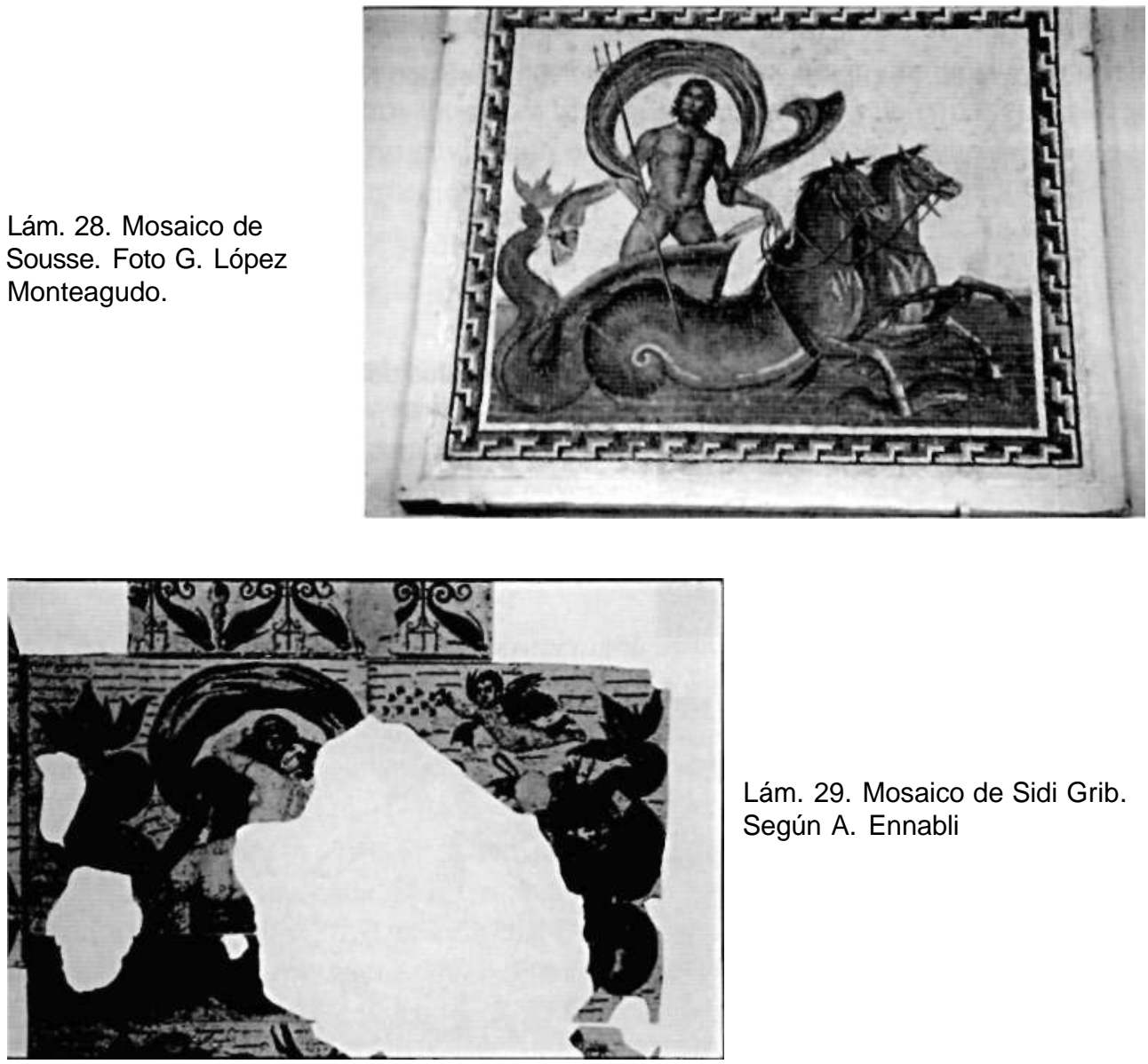

Lám. 29. Mosaico de Sidi Grib.

Según A. Ennabli 


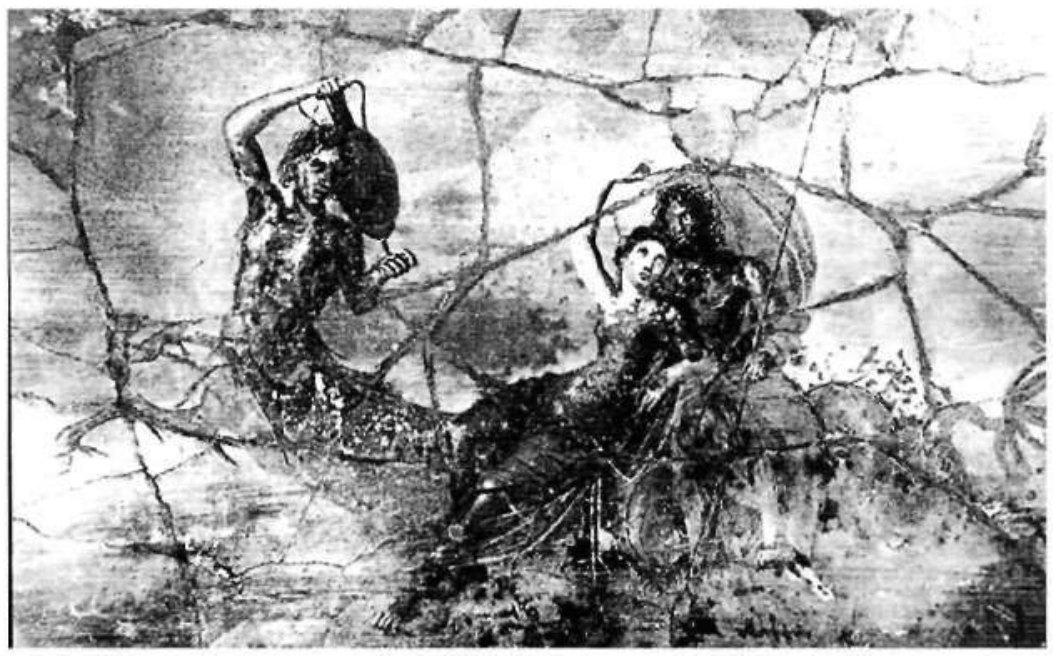

Lám. 30. Pintura de Pompeya. (LIMC VII, "Poseidon/Neptunus", núm. 94)

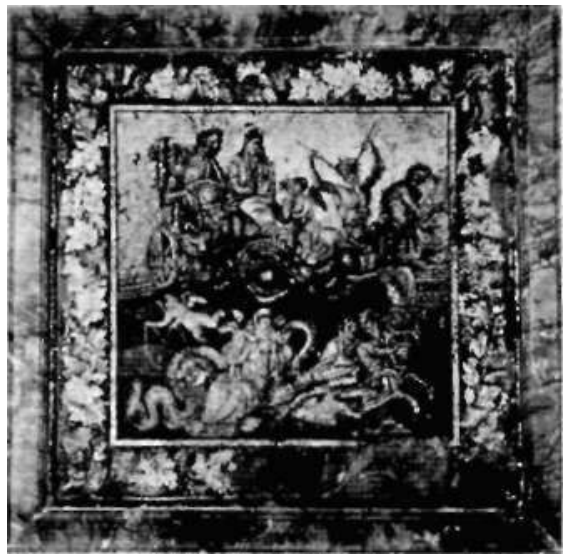

Lám. 31. Mosaico del Granduca de Toscana. Foto cortesía M.L. Neira

Lám. 32. Relieve de la Glyptoteca de Munich. Foto M.L. Neira.

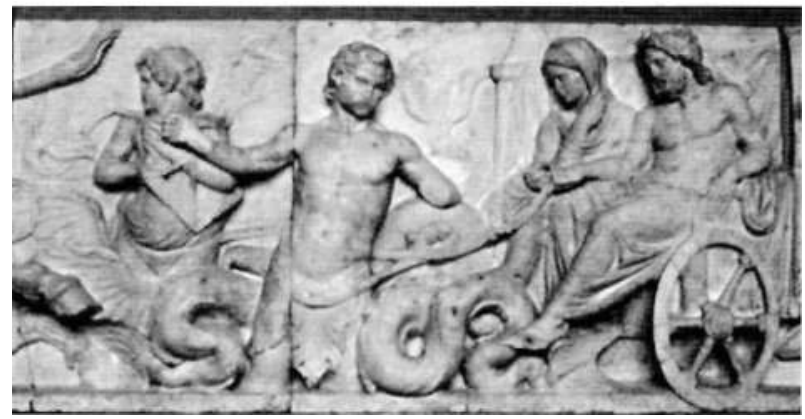

